\title{
Common Secondary Causes of Resistant Hypertension and Rational for Treatment
}

\author{
Charles Faselis, ${ }^{1}$ Michael Doumas, ${ }^{1}$ and Vasilios Papademetriou ${ }^{2}$ \\ ${ }^{1}$ Veterans Affairs Medical Center, George Washington University, VAMC 50 Irving Street NW, Washington, DC 20422, USA \\ ${ }^{2}$ Veterans Affairs Medical Center, Georgetown University, Washington, DC 20422, USA
}

Correspondence should be addressed to Charles Faselis, charles.faselis@med.va.gov

Received 8 November 2010; Accepted 11 January 2011

Academic Editor: Konstantinos Tsioufis

Copyright () 2011 Charles Faselis et al. This is an open access article distributed under the Creative Commons Attribution License, which permits unrestricted use, distribution, and reproduction in any medium, provided the original work is properly cited.

\begin{abstract}
Resistant hypertension is defined as uncontrolled blood pressure despite the use of three antihypertensive drugs, including a diuretic, in optimal doses. Treatment resistance can be attributed to poor adherence to antihypertensive drugs, excessive salt intake, physician inertia, inappropriate or inadequate medication, and secondary hypertension. Drug-induced hypertension, obstructive sleep apnoea, primary aldosteronism, and chronic kidney disease represent the most common secondary causes of resistant hypertension. Several drugs can induce or exacerbate pre-existing hypertension, with non-steroidal anti-inflammatory drugs being the most common due to their wide use. Obstructive sleep apnoea and primary aldosteronism are frequently encountered in patients with resistant hypertension and require expert management. Hypertension is commonly found in patients with chronic kidney disease and is frequently resistant to treatment, while the management of renovascular hypertension remains controversial. A step-by-step approach of patients with resistant hypertension is proposed at the end of this review paper.
\end{abstract}

\section{Introduction}

Hypertension represents a major public health problem affecting more than one billion individuals worldwide [1]. The advent of antihypertensive therapy has substantially reduced the occurrence of cardiovascular events. However, antihypertensive therapy failed to achieve blood pressure control in all patients, with hypertension control rates remaining in general disappointingly low. Blood pressure goals are not attained in some patients despite the simultaneous use of several antihypertensive medications. Several terms have been used to define this condition: "refractory hypertension", "difficult-to-treat hypertension", "difficult-tocontrol hypertension"; however, the term "resistant hypertension" seems to prevail.

Resistant hypertension is currently defined as uncontrolled blood pressure despite the use of optimal doses of three antihypertensive medications, of which one is a diuretic [2]. Several factors have been identified as contributors to resistant hypertension. Poor patient adherence, physician inertia, inadequate doses or inappropriate combinations of antihypertensive drugs, excess alcohol intake, and volume overload are some of the most common causes of resistance [2-10]. Secondary forms of hypertension represent another very important contributor to drugresistance. The list of secondary forms of hypertension is long and covers a large variety of conditions (Table 1). Most of these conditions may result in resistance to pharmacologic therapy of hypertension.

The management of patients with resistant hypertension requires a gratifying combination of clinical acumen and common sense. An extensive workup of all patients with uncontrolled hypertension is scientifically unsound, is very costly and requires immense human and technical resources. Therefore, practicing physicians need to implement evidence-based medicine. The effective management of patients with resistant hypertension requires an appropriate combination of physiology and pharmacology, taking into account the unique characteristics of each case in order to tailor the therapeutic approach to the individual patient.

This paper will address the most common secondary causes of resistant hypertension (drug-induced, obstructive sleep apnea, primary aldosteronism, and chronic kidney 
TABLE 1: Secondary forms of hypertension (disease categories).

(i) Endocrine disorders

(ii) Renal disease

(iii) Neurological disorders

(iv) Acute stress

(v) Drug-induced hypertension

(vi) Miscellaneous

disease), which are frequently encountered in hypertensive patients and are, therefore, the most interesting from the clinical point of view. In addition, this paper will attempt to provide a rational for the workup and treatment of patients with resistant hypertension.

\section{Prevalence and Prognosis of Resistant Hypertension}

The exact prevalence of resistant hypertension in the general population remains unknown. Data from small observational studies show a wide variation (from 5\% to 50\%) according to the studied populations [2-10]. Data from large clinical trials point towards a relatively high prevalence of resistant hypertension (20-35\%). It has to be noted, however, that atypical drug combinations have been used in most of these studies as required by study protocols. Therefore, the evaluation of the prevalence of resistant hypertension requires a large, prospective, population-based study, specially designed for this aim.

Similarly, the prognosis of resistant hypertension is currently unknown [2-10]. Available evidence addressing the prognosis of resistant hypertension is scarce, since virtually no longitudinal study has addressed this topic. Data from small clinical studies point towards an increased cardiovascular risk in patients with resistant hypertension. In addition, patients with resistant hypertension frequently have comorbidities that are known to increase cardiovascular morbidity and mortality, such as chronic kidney disease, diabetes, and obesity. Moreover, patients with resistant hypertension have higher rates of target organ damage than the general hypertensive population and are thus at increased cardiovascular risk.

\section{Lifestyle Factors}

Resistance to antihypertensive treatment is affected by several lifestyle factors. Excessive dietary salt intake is common in patients with resistant hypertension and contributes to treatment resistance by blunting the blood pressure reduction of most antihypertensive drugs, including diuretics and inhibitors of the renin-angiotensin axis [2-10].

Obesity can also contribute to treatment resistance [2-10]. It has been shown that blood-pressure control is more difficult to be achieved in obese than lean hypertensive patients. Several lines of evidence indicate a graded positive correlation between body mass index and blood pressure levels, while weight loss results in blood pressure reduction.
TABLE 2: Drugs inducing or exacerbating hypertension.
(i) Nonsteroidal anti-inflammatory drugs
(ii) Oral contraceptives
(iii) Sympathomimetics
(iv) Illicit drugs
(v) Glucocorticoids
(vi) Mineralocorticoids
(vii) Cyclosporine, tacrolimus
(iix) Erythropoietin
(ix) Herbal supplements
(x) VEGF inhibitors

Insulin resistance, sympathetic nervous system overactivity, sodium retention, and activation of the renin-angiotensin system have been implicated in the pathogenesis of obesityinduced hypertension.

Alcohol consumption is another important factor [210]. Large alcohol consumption ( $>3$ drinks per day) has been shown to result in blood pressure elevation. In addition, blood pressure control might be achieved more difficult in heavy drinkers due to poor adherence in antihypertensive therapy. The role of physical inactivity in patients with resistant hypertension has not been adequately studied.

\section{Drug-Induced Hypertension}

A variety of prescription or over the counter medicines as well as other exogenous substances may induce hypertension or contribute to treatment resistance. Drug-induced hypertension is among the most common causes of secondary hypertension and is frequently encountered in everyday clinical practice. However, despite the frequent occurrence of drug-induced hypertension, primary care physicians frequently miss the opportunity to detect and appropriately manage this iatrogenic form of secondary hypertension. Therefore, a detailed and meticulous medical history is of utmost importance in patients with resistant hypertension, since the identification and subsequent withdrawal of the offending drug may alleviate treatment resistance. However, withdrawal of the responsible agent is not always possible; in such cases, dose reduction and/or search for alternate treatment may substantially improve or even control blood pressure levels. Another very important aspect relates to the great variability of the effects of administered drugs on blood pressure. The administration of offending drugs can result in excessive blood pressure elevation in some individuals, while most individuals will experience little or no increases of blood pressure. This variability represents a rule without exception. Therefore, it would be very important to identify predictors of blood pressure elevation, in order to individualize drug treatment. Up to now, however, no such reliable predictors have been identified.

A descriptive list of all exogenous agents capable of inducing or exaggerating hypertension is presented in Table 2. However, this paper will focus on the drugs that are 
widely used, represent the most common causes of druginduced hypertension, and are thus of major clinical importance: nonsteroidal anti-inflammatory drugs (NSAIDs) and oral contraceptives. In addition, a brief comment regarding specific antineoplastic agents (anti-VEGF) that have emerged as inducers of hypertension is presented at the end of this chapter, since many clinicians are not aware of this condition.

4.1. NSAIDs-Induced Hypertension. By far, the most common cause of drug-induced hypertension is the use of NSAIDs. In 265 patients with resistant hypertension identified during a one-year period, treatment resistance was drugrelated in 36\% of the cases, with NSAIDs being responsible in $88 \%$ (personal unpublished data). Osteoarthritis is highly prevalent in the general population, and its prevalence would be even greater due to population aging and the obesity epidemic $[11,12]$. Osteoarthritis and hypertension often coexist, since both conditions are age related. It has been reported that approximately $50 \%$ of patients with osteoarthritis suffer from hypertension [13]. Although lifestyle modification, exercise, and weight loss are considered as first-line therapeutic measures for patients with osteoarthritis, the vast majority of such patients require the systematic or intermittent use of either acetaminophen or NSAIDs for pain relief.

Data regarding the effects of NSAIDs on blood pressure continue to accrue. Two large prospective cohort studies in normotensive women reported higher risks of subsequent hypertension among NSAIDs users than in women without regular NSAIDs administration $[14,15]$. In the first study, the risk of developing hypertension was increased about two times in women using acetaminophen or NSAIDs [14]. Acetaminophen consumption for 1-4 days per month and NSAIDs consumption for 5-14 days per month was necessary for the risk to be apparent. In the second study, women with frequent use of nonnarcotic analgesics (>22 days/month) had statistically significant higher risk for developing hypertension; in particular, the hazard ratios were 1.20 for acetaminophen, 1.21 for aspirin, and 1.35 for NSAIDs [15]. It has to be noted that although acetaminophen is considered to have a better safety profile than NSAIDs [16, 17], its use was associated with a moderate increase in the risk for incident hypertension in both males and females $[18,19]$. Another large, case-control study revealed a $66 \%$ increased risk for initiating antihypertensive drugs in NSAIDs users compared to nonusers [20]. These detrimental effects of NSAIDs on blood pressure have been also observed in two older meta-analyses of randomized trials with NSAIDs $[21,22]$. In the first meta-analysis, mean arterial pressure was increased by $3.3 \mathrm{mmHg}$ in hypertensive patients whereas the increase in normotensive subjects was negligible $(1.1 \mathrm{mmHg})$ [21]. In the second meta-analysis, NSAIDs resulted in a significant mean arterial pressure elevation of $5.0 \mathrm{mmHg}$; blood pressure elevation was apparent in hypertensive patients with controlled blood pressure, whereas normotensive individuals did not experience such an effect [22].
On the contrary, data reporting no or little effect of NSAIDs on blood pressure exist in the literature as well. In two cross-sectional studies, no association between use of NSAIDs and hypertension was found [23, 24]. Similar findings were observed in two small randomized studies regarding the effects of acetaminophen on blood pressure [25, 26], as well as in studies evaluating the effects of aspirin on blood pressure in hypertensive patients [27, 28]. In addition, in a large prospective cohort of 8,229 male normotensive physicians, analgesic use was not associated with increased risk of developing hypertension (hazard ratio: 1.12; $95 \%$ CI: 0.97-1.31) [29]. The corresponding hazard ratios were 1.08 (95\% CI: 0.87-1.34) for acetaminophen, 1.16 (95\% CI: 0.92-1.48) for aspirin, and 1.05 (95\% CI: 0.89-1.24) for NSAIDs.

This apparent heterogeneity of available data on the effects of traditional NSAIDs on blood pressure becomes even more complicated when recent data with selective COX2 inhibitors are taken in account. In a meta-analysis of randomized trials, use of COX-2 inhibitors was associated with a significant increase in blood pressure compared to placebo $(3.85 / 1.06 \mathrm{mmHg})$ and nonselective NSAIDs $(2.83 / 1.34 \mathrm{mmHg})[30]$. However, it was shown that a great part of blood pressure elevation could be attributed to rofecoxib. Indeed, rofecoxib use is associated with greater blood pressure elevations than celecoxib in both hypertensive and normotensive individuals [31].

The above-mentioned study highlights another important aspect: the potential differences on blood pressure effects between the various NSAIDs. In a meta-analysis of randomized trials, conducted mainly in hypertensive patients, naproxen and indomethacin were associated with the largest blood pressure elevations, while piroxicam, sulindac, ibuprofen, and aspirin exhibited little if any effect on blood pressure [21]. On the contrary, a randomized study in patients with controlled hypertension showed that the blood pressure was significantly higher with ibuprofen than with lumiracoxib [32]. Moreover, in 34,701 participants at the MEDAL (Multinational Etoricoxib and Diclofenac Arthritis Long term) program, patients assigned to etoricoxib discontinued the study due to hypertension more frequently than patients randomized to diclofenac [33].

Finally, the potential differences of the effects of NSAIDs on blood pressure according to the various antihypertensive agents coadministered are of great clinical importance. In a study of elderly hypertensives with osteoarthritis, indomethacin had no effect on blood pressure in patients taking calcium antagonists whereas significant blood pressure elevations were detected in patients taking ACE-inhibitors [34]. On the contrary, celecoxib exerted similar to placebo effects in patients taking ACE-inhibitors [35]. Another study among hypertensive patients with osteoarthritis, comparing the effects of rofecoxib and celecoxib, revealed no differences on blood pressure between the two drugs in patients taking diuretics or calcium antagonists, whereas larger blood pressure elevations were observed with rofecoxib than with celecoxib in patients taking ACE-inhibitors or beta blockers [36]. 
The above presented information clearly indicates that available data on the effects of NSAIDs on blood pressure are sometimes contradictory and in total far from conclusive. Convincing data coming from carefully designed randomized studies are necessary to: (a) detect potential differences between the various NSAIDs on blood pressure, (b) clarify the effects of coadministering each NSAID with each one of the various antihypertensive drug categories, and (c) identify predictors of blood pressure response to NSAIDs use.

Withdrawal of NSAIDs is indicated in patients with resistant hypertension, exacerbation of prior hypertension, or incident hypertension. Substituting NSAIDS with acetaminophen can usually solve the problem. Pain relief is more likely in patients with osteoarthritis and pain of muscular skeletal origin. However, this is not always possible in everyday clinical practice, since patients with chronic inflammatory arthritic diseases (rheumatoid arthritis) respond better to anti-inflammatory agents. In such cases, hydrocodone, tramadol, or nerve blocking might be of help, constituting effective alternatives to NSAIDs. In cases, however, where NSAIDs are still necessary, the lower effective dose should be administered, since existing data point towards dose-related effects of NSAIDs on blood pressure.

NSAIDs affect blood pressure levels via different mechanisms: activation of the renin-angiotensin-aldosterone system, sodium and water retention, induction of vasoconstriction through endothelin-1 and arachidonic acid metabolites, and mainly inhibition of renal vasodilatory prostaglandins $\left(\mathrm{E}_{2}\right.$ and $\mathrm{I}_{2}$ ) [37-43]. These detrimental effects of NSAIDs may lead to deterioration of renal function and acute kidney injury, especially in patients of older age, preexisting hypertension, chronic kidney disease, or diabetes. In such patients, calcium antagonists seem to be more suitable than drugs inhibiting the renin-angiotensin system, since the concomitant administration of NSAIDs and calcium antagonists is not accompanied by blood pressure elevation $[36,39]$. The development of NSAIDs that apart from cyclooxygenase inhibition possess nitric oxide promoting properties might significantly ameliorate current situation and alleviate the effects of NSAIDs on blood pressure. CINODs (Cyclo-oxygenase Inhibiting Nitric Oxide Donating drugs) represent a new class of NSAIDs; CINOD molecules consist of a traditional NSAID and a nitric oxide-donating chemical group connected by a linker. Naproxcinod is the first CINOD in clinical trials with very promising preliminary results [44-47].

4.2. Oral Contraceptives. Oral contraceptives represent another class of drugs that are widely used and are capable of inducing hypertension $[48,49]$. The larger study evaluating the effects of oral contraceptives on blood pressure was the Nurses' Health Study, in which more than 60,000 normotensive women were prospectively followed for 4 years [50]. Women using oral contraceptives had an $80 \%$ higher risk of developing hypertension compared to women that were not using such drugs. However, withdrawal of oral contraceptives abolished this increased risk, underlining the need for close monitoring in women taking oral contraceptives. Another important aspect of "pill"-induced hypertension regards the contribution of oral contraceptives in uncontrolled hypertension. A study in hypertensive women revealed that those taking oral contraceptives had more severe hypertension and lower blood-pressure control rates than women using other contraceptive methods [51].

The type of oral contraceptives seems also to be of clinical importance. Combined oral contraceptives (progestin and estradiol), which were widely used in the past, were associated with blood pressure elevations more frequently than progestin-only oral contraceptives. On the contrary, drospirenone (a fourth generation progestin) reduces blood pressure when combined with estradiol [52]. Therefore, current guidelines recommend the use of progestin-only oral contraceptives in women with established cardiovascular disease, or major cardiovascular risk factors (such as hypertension) $[53,54]$.

It can, therefore, be summarized that oral contraceptives may contribute to resistance in hypertensive women, but the type of oral contraceptive is important. Close monitoring of women and withdrawal of oral contraceptives may alleviate the effects on blood pressure.

4.3. Anti-VEGF Agents. Another class of agents that emerged as inducers of hypertension are the antineoplastic drugs that target the VEGF pathway. A monoclonal antibody (bevacizumab) binding to the VEGF-A isoform, as well as small molecules inhibiting the intracellular tyrosine kinase domains of all three VEGF receptors, is used or is under clinical testing for the treatment of various malignancies [55-57]. Hypertension was encountered very frequently in patients receiving treatment with VEGF-inhibitors [58]. In particular, $20-30 \%$ of patients treated with bevacizumab, and $15-60 \%$ of patients treated with VEGF kinase inhibitors developed hypertension [59]. Three meta-analyses with drugs inhibiting the VEGF pathway uncovered a high relative risk for incident hypertension with these agents: 7.5 (95\% CI: 4.2-13.4) with bevacizumab, 6.11 (95\% CI: 2.44-15.32) with sorafenib, and 21.6 (95\% CI: 18.7-24.8) with sunitinib [60$62]$. Interestingly enough, the development of hypertension has been correlated with the efficacy of these drugs [63-65], suggesting that hypertension could be used as a surrogate marker of anti-VEGF efficacy. A phase III trial evaluates this concept in patients with pancreatic cancer receiving antiVEGF agents. Clearly, more data are needed to clarify the blood pressure effects of the various drugs acting on the VEGF pathway.

Experimental studies have shown that VEGF upregulates endothelial nitric oxide synthase $[66,67]$, enhances nitric oxide production [68], and induces nitric oxide-dependent vasorelaxation [69]. Moreover, VEGF was shown to result in enhanced prostacyclin production and release $[70,71]$. It can be therefore anticipated that VEGF inhibition may lead to reduction of nitric oxide and prostacyclin bioavailability, a subsequent increase of systemic vascular resistance, and finally blood pressure elevation. In addition, arteriolar rarefaction has been observed in animals treated with VEGF kinase inhibitors, proposing another pathogenetic 
mechanism of hypertension with these drugs [72-74]; preliminary studies in humans reported similar findings [75, 76]. Finally, enhanced arterial stiffness has been suggested as another contributing factor in the development of hypertension [77].

The recognition of the pathogenetic mechanisms that contribute to blood pressure elevation with VEGF-inhibitors might be helpful in identifying the most appropriate drugs for the management of these patients. Reliable data evaluating the efficacy of the various antihypertensive drug categories in anti-VEGF-induced hypertension are missing. Preliminary reports point towards restricted efficacy of diuretics [78] and beneficial effects of calcium antagonists [79]; however, appropriate prospective studies are needed in this topic.

\section{Obstructive Sleep Apnea}

A vast amount of evidence demonstrates an association between obstructive sleep apnea (OSA) and hypertension. Such an association has been shown in epidemiological, longitudinal, and cross-sectional studies, as well as in studies from specialized clinics [80-83]. In addition, it has been shown that OSA in normotensive subjects predicts future development of hypertension.

Sympathetic nervous system activation plays a crucial role in the pathogenesis of hypertension in patients with OSA. Enhanced upper airway resistance and intermittent hypoxia are considered to stimulate the sympathetic system, while the subsequent sympathetic overactivity may result in blood pressure elevation via vasoconstriction and increased systemic vascular resistance, increased cardiac output, and enhanced fluid retention. Aldosterone seems to be the other significant player in this field. Increased aldosterone levels have been observed in OSA patients with resistant hypertension. The exact nature of the association between OSA and aldosterone excess remains to be elucidated. Whether OSA results in aldosterone excess or aldosterone excess contributes to OSA, or another underlying factor (like obesity) promoting both aldosterone excess and OSA has not been clarified.

Several studies have reported an extremely high prevalence of OSA in patients with resistant hypertension. Two decades ago, a Swedish study of 16 patients with resistant hypertension reported a $56 \%$ prevalence of OSA in these patients compared to $19 \%$ in patients with controlled hypertension [84]. In a study of 41 consecutive resistant hypertensives, an $83 \%$ prevalence of unsuspected OSA was found; OSA was defined as an apnea/hypopnea index (AHI) of more than 10 events per hour [85]. Another study of 71 patients with resistant hypertension revealed an $85 \%$ prevalence of OSA (AHI $\geq 5$ events/h) [86]. A study from Spain in 62 resistant hypertensives reported a $90 \%$ prevalence of OSA (AHI $\geq 5$ events/h) [87]. However, when the diagnosis of OSA was based on 30 or more episodes of apnea/hypopnea per hour, the prevalence was reduced to $70 \%$, underlining the importance of accurate and homogeneous definition of OSA. Moreover, all the above-mentioned recent studies did not have a control group in order to exclude the potential effects of confounding factors. A recent study from Brazil evaluated 63 patients with resistant hypertension and an equal number of patients with controlled hypertension, matched for baseline parameters apart from blood pressure [88]. A strong and independent association between OSA and resistant hypertension has been described (odds ratio: 4.8; 95\% CI: $2.0-11.7$ ); OSA (AHI $\geq 10$ events/h) in $71 \%$ of resistant hypertensives and in $38 \%$ of responders.

Continuous positive airway pressure (CPAP) represents the treatment of choice for patients with OSA. It has been shown that CPAP decreases the incidence of cardiovascular events in patients with OSA $[89,90]$.The acute application of CPAP attenuates blood pressure elevations during sleep [91]. However, the long-term effects of CPAP on blood pressure are controversial, from studies reporting a significant decrease in blood pressure to studies reporting small or no effects [92-106]. Three meta-analyses have tried to overcome these discrepancies and revealed that the beneficial effect is modest, with reductions in systolic blood pressure ranging from $1.38 \mathrm{mmHg}$ to $2.46 \mathrm{mmHg}$ [107-109]. It is, therefore, not surprising that in a recent randomized study, valsartan was more effective than CPAP in hypertensive patients with OSA [110].

It has to be noted, however, that most of the abovementioned studies have not been performed exclusively in hypertensive patients, usually evaluating both normotensive and hypertensive subjects. In addition, larger blood pressure reductions were observed in OSA patients with higher baseline blood pressure levels $[107,111]$, as expected with any antihypertensive approach; the motto "the higher the blood pressure, the larger the reduction" has been verified over the years. Indeed, two small studies in OSA patients with resistant hypertension revealed significant blood pressure reductions (over $10 \mathrm{mmHg}$ ) $[112,113]$. On the contrary, a study in 42 patients with resistant hypertension showed a smaller mean arterial pressure reduction $(5.6 \mathrm{mmHg}$; $95 \%$ CI: $2.0-8.7 \mathrm{mmHg} ; P<.03$ ) [114]. Interestingly enough, the benefits of CPAP were evident only at 1 -year after CPAP application, suggesting that longer followup periods might be necessary for the benefits of CPAP treatment to become apparent in OSA patients with resistant hypertension. Another important factor is that CPAP treatment allowed de-escalation of antihypertensive treatment in the majority of participating patients (71\%) [114]. A recent study in 96 patients with OSA and resistant hypertension showed a slight decrease in systolic blood pressure $(1.3 \mathrm{mmHg})$ [115]. However, the reduction was significantly larger in patients with ABPM-confirmed resistant hypertension $(7.6 \mathrm{mmHg})$. In addition, the reduction was even larger in CPAP users for more than 5.8 hours per day. The above-mentioned data delineate the complexity in identifying patients with resistant hypertension and OSA that will have the greater benefits with CPAP treatment.

An important issue challenging the efficacy of CPAP relates to patient adherence. Among patients prescribed CPAP therapy up to $50 \%$ failed to initiate it or did not use it at 3 years $[116,117]$. Moreover, among CPAP users, $29-83 \%$ used it for less than 4 hours [118].

Another important aspect of treatment is the choice of antihypertensive drugs in patients with OSA. The crucial role 
of SNS activation and the increased levels of aldosterone in patients with OSA, point towards potential advantages of drugs inhibiting these pathways on reducing blood pressure. Indeed, beta blockers were found to be more effective than other antihypertensive drugs in OSA patients [119]; however, relevant data is still far from conclusive. Even more interestingly, however, spironolactone was shown not only to significantly lower blood pressure in 12 patients with OSA and resistant hypertension, but to reduce the severity of OSA as well [120]. Further, larger studies are needed, however, to confirm these beneficial effects of spironolactone in patients with OSA.

\section{Primary Aldosteronism}

Primary aldosteronism (PA) was initially described by Conn in 1955 [121]. PA is characterized by autonomous production of aldosterone by adrenal glands and the subsequent decrease in renin levels though negative feedback. Aldosterone excess leads to hypertension, metabolic alkalosis, hypernatremia, and potassium loss resulting in hypokalemia; the latter is currently considered a late manifestation of PA. PA can result from an aldosterone producing adenoma, bilateral adrenal hyperplasia, glucocorticoid-remediable aldosteronism, or rare familial syndromes. Although the diagnosis of adrenal adenomas prevailed during the older times, recent reports reveal that hyperplasia is more frequent than adrenal adenomas.

The prevalence of PA in the general hypertensive population remains an unresolved issue $[122,123]$. Historically, $\mathrm{PA}$ has been considered a rare disease, affecting about $1 \%$ of hypertensive patients [124-127]. However, several studies performed in the last decade report a much higher prevalence of PA (>10\%), suggesting an "epidemic" of this condition [128-133]. These studies, however, were carried out in specialized referral centers, raising concerns of selection bias. Indeed, a study of more than 600 unselected patients with hypertension conducted in Chile, revealed a $6.1 \%$ prevalence of PA [134], suggesting that the true prevalence is somewhere in the middle. However, irrespective of its exact prevalence, PA has become fashionable again, with leading specialized centers appearing all over the world, from Alabama (D. Calhoun) to Italy (G. Rossi) and from Australia (M. Stowasser) to United Kingdom (M. Brown).

The prevalence of hypertension relates to the severity of hypertension. In the study from Chile, PA was found in $1.99 \%$ of patients with Stage I hypertension and in $13.2 \%$ of patients with stage III hypertension [134]. In another study of more than 400 Czech patients with moderateto-severe hypertension, the prevalence of PA was even higher (19\%) [135]. Data from clinical practice indicates that resistant hypertension represents the condition with the highest probability of detecting PA $[136,137]$. Indeed, the prevalence of PA ranged from $14-23 \%$ in 5 studies conducted in resistant hypertensives [138-142]. A study of 88 patients with resistant hypertension in Alabama showed that 18 patients $(20 \%)$ suffered from PA; PA prevalence was race independent [138]. The prevalence of PA was quite
TABLE 3: Endocrine causes of secondary hypertension.
(i) Primary aldosteronism
(ii) Pheochromocytoma
(iii) Hyperthyroidism
(iv) Hypothyroidism
(v) Cushing's syndrome
(vi) Acromegaly
(vii) Hyperparathyroidism
(iix) Carcinoid tumor
(ix) Congenital adrenal hyperplasia

similar in two other studies, one from Seattle (17\%) and one from Norway (23\%) [139, 140]. A somehow lower prevalence was found in the remaining two studies. A study from Spain reported a 14\% prevalence of primary hyperaldosteronism in patients with refractory hypertension; however, patients with hypokalemia were excluded from the study suggesting that the true prevalence of primary aldosteronism could be up to two times higher than the one reported [141]. Finally, a similar prevalence of $14 \%$ has been reported in diabetic subjects with resistant hypertension [142].

The above-mentioned studies have reported a PA prevalence of $14-23 \%$ in patients with resistant hypertension, suggesting that the true prevalence would be around $20 \%$. However, it has to be recognized that all these studies included a small number of patients. In total, only 418 patients participated in these studies, underlining the need for larger studies. A recent study from Greece evaluated 2,032 patients with resistant hypertension, with 1,616 of them having "true" resistant hypertension [143]. It was found that about $21 \%$ of studied patients had a high aldosterone to renin ratio combined with high aldosterone levels, which were suggestive of primary aldosteronism. However, only half of them $(11.3 \%)$ were suffering for primary aldosteronism, confirmed by salt suppression tests and response to spironolactone.

Another very interesting finding is the coexistence of $\mathrm{PA}$ and OSA in patients with resistant hypertension. In one study of 109 patients with resistant hypertension, OSA was found in $84 \%$ of patients with PA [144]. However, in another study, PA was found in only $34 \%$ of patients with OSA [145]. The pathophysiologic mechanisms underlining the co-occurrence of these conditions need further elucidation.

The other forms of endocrine hypertension, presented in Table 3, are less frequently encountered in hypertensive patients and, therefore, represent rare causes of resistant hypertension. In addition, the clinical presentation of these endocrine forms of secondary hypertension is usually so characteristic that is really hard to be missed. Since this paper addresses the most common secondary causes of resistant hypertension, readers interested in endocrine hypertension may refer to other recently published reviews [146, 147]. 


\section{Chronic Kidney Disease}

Hypertension is commonly found in patients with chronic kidney disease (CKD), with $75 \%$ of CKD patients taking antihypertensive drugs [148]. On the other hand, renal disease represents one of the forms of target organ damage induced by hypertension [149]. It seems that the relationship between hypertension and CKD is bidirectional; the kidney is both "the victim and the culprit" in this relationship.

All recent guidelines recommend lower blood pressure goals in patients with CKD, especially when frank albuminuria is present [149-151]. It has been shown, however, that the vast majority ( $>85 \%$ ) of patients with CKD fail to achieve these goals; blood pressure control rates in CKD patients are lower than in other hypertensive patients despite the use of 3 antihypertensive drugs in average [152, 153]. It is, therefore, not surprising that the prevalence of resistant hypertension in patients with CKD is over 50\% [154]. However, CKD is usually underappreciated as a cause of resistant hypertension, mainly because these patients are being followed at specialized nephrology clinics.

Several factors contribute to treatment resistance in patients with CKD. Sodium and fluid retention plays a cardinal role, while the increased activity of both the sympathetic and the renin-angiotensin-aldosterone systems greatly contribute to treatment resistance. Moreover, vascular alterations both at a structural and functional (increased endothelin-1, decreased nitric oxide bioavailability) level, combined with the consequences of renal ischemia play an additional role [155].

Another significant contributor to treatment resistance in patients with CKD regards the use of diuretics in these patients. It has been observed that restrictions in diuretic use were the primary cause of resistant hypertension in patients with CKD [156]. Restricted diuretic use includes either lower doses or inappropriate drug selection; thiazides are usually not effective when GFR is lower than 40 and should, therefore, be replaced by loop diuretics in such patients. In the case that furosemide is chosen, it has to be given at least twice daily due to its limited half-life. Finally, dietary salt reduction may effectively attenuate volume expansion and offer significant benefits in these patients.

Another important key aspect in patients with CKD is the assessment of urinary albumin excretion. Microalbuminuria and especially macroalbuminuria are related with marked increments in cardiovascular risk. Drugs inhibiting the rennin-angiotensin axis (ACE-inhibitors, angiotensin receptor blockers, and direct rennin inhibitors) should be included in the therapeutic regime, since their use is associated with reduction of albuminuria and end-stage renal disease [157]. The combination of ACE-inhibitors with angiotensin receptor blockers has not proven any benefits in high-risk patients at the ONTARGET study and was even associated with more adverse effects $[158,159]$. However, this combination might still be beneficial in patients with CKD and overt albuminuria [160].

Renovascular hypertension is another common form of secondary hypertension. Renovascular hypertension is of atherosclerotic origin in the vast majority of cases, thus being more frequent in older individuals, diabetics, smokers, and in patients with atherosclerotic lesions at other vascular beds $[161,162]$. Indeed, about $25 \%$ of patients undergoing cardiac catheterization are found to have renal artery stenosis (RAS) higher than $70 \%$, which could be of clinical significance $[163,164]$. On the other hand, fibromuscular dysplasia is a much less frequent cause of RAS (approximately 10\%) than atherosclerosis, and is more frequently encountered in younger females.

Renovascular hypertension is common among patients with resistant hypertension. Older studies suggested that 1 out of 3 patients with secondary hypertension has renovascular hypertension $[165,166]$. Unfortunately, recent studies in patients with resistant hypertension usually focus on OSA and PA and do not even mention RAS. It seems that RAS came out of fashion, mainly because its diagnosis with noninvasive methods remains tricky. Although several methods are used for the detection of RAS (duplex ultrasound, renal scintigraphy, ands CT and MR angiography) with rather good sensitivity and specificity [167], the diagnosis of renovascular hypertension represents an unfulfilled challenge for primary care physicians and remains mainly restrained in specialized centers.

Another important aspect regards the management of patients with RAS. Three choices are available nowadays: surgical treatment, balloon angioplasty (with or without stenting), and conservative drug treatment. The surgical approach has subsided during the last decades and is now reserved for specific indications. Available data regarding the remaining two methods are inconclusive. Balloon angioplasty was not found superior to optimal drug treatment in the recently published ASTRAL study; several drawbacks, however, limit the interpretation of study findings [168]. Another ongoing trial, the CORAL study, will provide hardendpoint data with the two different approaches [169].

\section{Rational for the Management of Resistant Hypertension}

The management of resistant hypertension represents a challenge for the astute clinician. Although it seems rational for patients with resistant hypertension to be referred to specialized hypertension clinics, the initial evaluation can be performed by primary care physicians. We will, therefore, attempt to provide a step-by-step approach for the evaluation and treatment of patients with resistant hypertension. The first steps may take place at the primary care level, in the attempt to substantially reduce the number of referred patients and prevent unnecessary costs and patient discomfort.

In summary, the following steps need to be followed in the management of resistant hypertension.

(i) Verification of "true" Resistant Hypertension. Patients with "pseudoresistance" should be identified and excluded from further evaluation. Three main problems require special attention at this step: patient-related problems, physician-related problems, and blood-pressure techniquerelated problems. 
(a) Patient-Related Problems. Adherence to antihypertensive treatment is of utmost importance for the effective management of arterial hypertension. Both epidemiological and clinical data strongly indicate that patient adherence to antihypertensive therapy is poor [170-175]. Almost half of treated hypertensive patients discontinue drug administration during the first year of treatment whereas long-term adherence rates are even lower. In addition, small studies in patients with resistant hypertension suggest that poor patient adherence represents one of the most common causes of treatment resistance $[176,177]$. Detailed medical history, information by relatives, and use of specific questionnaires might help in identifying patients with poor adherence; these methods can be easily applied by primary care physicians with obvious benefits. The pursuit of improved patient adherence attracts great scientific interest. Modern technology is used with good results (electronic pill boxes, internet monitoring) but is not widely applied yet. Special programmes using close contact of health care professionals (doctors, nurses, and pharmacists) with patients seem also effective but lack wide application as well. Finally, simplification of dosing schedule and use of drugs with superior safety profile may be of benefit.

(b) Physician-Related Problems. Physician inertia is another important factor contributing in treatment resistance. It has been shown that doctors are frequently reluctant to maximize drug therapy, either by adding antihypertensive drugs or by switching drug category, in order to achieve blood pressure goals [178-181]. Indeed, a gap between guideline recommendations and their implementation in everyday clinical practice has been recognized and represents a significant obstacle in achieving satisfying blood pressure control rates $[149,150]$. Another contributor to treatment resistance is the use of inappropriate drug combinations or suboptimal doses of antihypertensive drugs. Indeed, a study of patients with resistant hypertension revealed that simple measures, such as increasing diuretic dosing or switching to appropriate diuretics, can result in significant blood pressure reductions [156].

In our opinion, however, the most important line of evidence suggesting physician inertia on treatment resistance, comes from recent studies reporting significantly higher control rates of hypertension [182-185]. In these studies, various measures have been used to motivate physicians in achieving blood pressure goals, resulting in improved control rates. Therefore, physicians need to be the focus of future efforts for the effective management of resistant hypertension.

(c) Blood Pressure Technique-Related Problems. The requirements for proper blood pressure measurement have been standardized [186] and incorporated in the guidelines for the management of arterial hypertension $[149,150]$. However, the measurement of office blood pressure in clinical practice frequently deviates from the recommendations. Therefore, falsely elevated blood pressure levels may be recorded due to several reasons: inappropriate cuff size, failure to comply with the recommendations regarding sufficient time before blood-pressure measurement, arm support at the heart level, assessment in a quiet room, triplicate recordings, and coffee intake or smoking before blood pressure measurement [187189]. The above mentioned factors may contribute to overestimation of blood pressure and "pseudoresistance". Similarly, false elevations may be encountered in older patients, in whom adequate artery compression may not be achieved due to marked arterial calcification. Therefore, it is essential to assure proper techniques of blood pressure measurement in order to limit the rates of pseudoresistance.

Another important aspect of "resistance" is recognition of "white coat" hypertension. It has been noted that in $20-30 \%$ of patients with resistant hypertension, treatment resistance may be attributed to the "white coat" effect [143, 190-192]. Target organ damage is less frequent in these patients, who actually do not suffer from "true" resistant hypertension. Therefore, either ambulatory or home blood-pressure monitoring should be performed in every patient with resistant hypertension, in order to exclude the "white coat" effect and avoid unnecessary referrals.

(ii) Exclusion of Drug-Induced Hypertension. As discussed in the first section of this paper, several drugs may induce blood pressure elevations, with NSAIDs and oral contraceptives being the most common. Therefore, practicing physicians need to be very meticulous during medical history taking, in order to uncover the use of drugs inducing hypertension. The withdrawal of offended drugs usually results to the return of blood pressure at previous levels. In the case, however, that the drug is considered essential for the treatment of comorbidities, the substitution to another drug with a more friendly profile or the reduction of dose might be beneficial.

(iii) Reduction of Dietary Sodium Intake. Sodium intake is excessive in the Western world, mainly due to the "hidden salt" in processed foods. The average sodium intake is far higher than the recommended 2.4 grams per day, reaching even $10 \mathrm{~g} /$ day in patients with resistant hypertension [193]. Plasma volume expansion represents one of the cardinal characteristics of resistant hypertension. The important role of sodium restriction in patients with resistant hypertension is highlighted by the findings of a recent study. It was found that reductions in sodium intake are accompanied by significant reductions in blood pressure levels in resistant hypertensives [194]. 
(iv) Evaluation for Secondary Causes of Hypertension. As previously discussed, obstructive sleep apnea, primary aldosteronism, and chronic kidney disease represent the most common secondary causes of resistant hypertension whereas several other conditions may be responsible for treatment resistance as well. The diagnostic workup for secondary hypertension is demanding, requires special knowledge and technology, and should be performed in specialized referral centers, which are familiar with secondary hypertension. Although a detailed description of the diagnostic workup is beyond the scope of this paper, some signs and/or findings raising the suspicion of secondary hypertension need to be mentioned. In particular: obesity, snoring, daytime sleepiness, and increased neck diameter raise the suspicion of obstructive sleep apnea; hypokalemia (either spontaneous or diuretic induced) is present in about half of cases with primary aldosteronism; active urine sediment, small kidneys, and impaired renal function point towards chronic kidney disease; abdominal bruit, difference in renal size raise the suspicion of renal artery stenosis..

(v) Pharmacologic Management of Resistant Hypertension. The pathophysiology of resistant hypertension provides the rational for the effective management of this clinical entity. The combination of increased systemic vascular resistance with marked volume expansion in many cases, renders the triple combination of a drug inhibiting the reninangiotensin axis (ACE-inhibitors or angiotensin receptor blockers) with a calcium antagonist and a diuretic a very attractive combination for the majority of patients (unless these drugs are contraindicated or not tolerated, or other drugs are indicated due to comorbidities). However, reliable data verifying the superiority of this combination over other combinations is not available. Special attention has to be drawn in maximizing the dose of diuretics or switching to loop diuretics in patients with low GFR. The overactivation of the sympathetic nervous system renders beta blockers, alpha blockers, and centrally acting antihypertensive drugs (clonidine, alpha methyldopa) of potential benefit in many patients when added in previous therapy. Direct vasodilators, such as hydralazine and minoxidil, can be very effective for blood pressure management, especially in African Americans and patients with chronic kidney disease. A vast amount of evidence indicates that spironolactone is a drug of choice in the treatment of resistant hypertension. Several studies revealed impressive blood pressure reductions in patients with resistant hypertension when spironolactone was added in the therapeutic regime [195-205]. Chronotherapy represents an important approach for the management of resistant hypertension. Administration of one antihypertensive drug at bedtime has been shown to improve blood pressure control in patients with resistant hypertension [206-208].

(vi) Newer Drugs for the Management of Resistant Hypertension. Endothelin antagonists exhibited promising results in preliminary studies [209]. The future of darusentan remains unclear, however, since in another study in patients with resistant hypertension, darusentan failed to be more effective than placebo regarding office blood pressure reductions. It has to be mentioned, however, that in the latter study, significant differences were detected in ambulatory blood pressure between darusentan and placebo [210], indicating that further studies are needed with this drug category. Another interesting approach for the management of resistant hypertension is the administration of nitric oxide donors. In a recent small clinical study of six patients with resistant hypertension, the combination of nitrates with phosphodiesterase- 5 inhibitors resulted in significant blood pressure reduction [211]. However, this finding has to be interpreted with caution, since the concomitant use of these medications is contraindicated due to the possibility of severe hypotension.

(vii) Interventional Management of Resistant Hypertension. Despite the wide application of antihypertensive therapy, a substantial portion of the hypertensive population remains uncontrolled although taking more than three drugs. This situation calls for testing alternative approaches in patients with resistant hypertension. Carotid baroreceptors and renal sympathetic overdrive play a significant role in blood pressure regulation $[212,213]$. During the last decade, two new approaches have revived the use of interventional techniques for the management of resistant hypertension. Carotid baroreceptor stimulation and renal sympathetic denervation have shown promising preliminary results in patients with resistant hypertension $[214,215]$. However, further studies are needed to establish their role in the management of resistant hypertension.

\section{References}

[1] P. M. Kearney, M. Whelton, K. Reynolds, P. Muntner, P. K. Whelton, and J. He, "Global burden of hypertension: analysis of worldwide data," Lancet, vol. 365, no. 9455, pp. 217-223, 2005.

[2] D. A. Calhoun, D. Jones, S. Textor et al., "Resistant hypertension: diagnosis, evaluation, and treatment: a scientific statement from the American Heart Association Professional Education Committee of the Council for High Blood Pressure Research," Hypertension, vol. 117, no. 25, pp. e510-e526, 2008.

[3] J. P. Garg, W. J. Elliott, A. Folker, M. Izhar, and H. R. Black, "Resistant hypertension revisited: a comparison of two university-based cohorts," American Journal of Hypertension, vol. 18, no. 5, pp. 619-626, 2005.

[4] D. P. Papadopoulos and V. Papademetriou, "Resistant hypertension: diagnosis and management," Journal of Cardiovascular Pharmacology and Therapeutics, vol. 11, no. 2, pp. 113118, 2006.

[5] P. A. Sarafidis and G. L. Bakris, "Resistant hypertension. An overview of evaluation and treatment," Journal of the American College of Cardiology, vol. 52, no. 22, pp. 17491757, 2008.

[6] M. H. Alderman, "Resistant hypertension: a clinical syndrome in search of a definition," American Journal of Hypertension, vol. 21, no. 9, pp. 965-966, 2008. 
[7] M. Moser, W. Cushman, and J. Handler, "Resistant or difficult-to-treat hypertension," Journal of Clinical Hypertension, vol. 8, no. 6, pp. 434-440, 2006.

[8] J. Amar, "Patients with resistant hypertension.", Journal of Hypertensionn, vol. 25, pp. S3-S6, 2007.

[9] M. Epstein, "Resistant hypertension: prevalence and evolving concepts," Journal of Clinical Hypertension, vol. 9, no. 1, pp. 2-6, 2007.

[10] R. Pisoni, M. I. Ahmed, and D. A. Calhoun, "Characterization and treatment of resistant hypertension," Current Cardiology Reports, vol. 11, no. 6, pp. 407-413, 2009.

[11] A. D. Woolf and B. Pfleger, "Burden of major musculoskeletal conditions," Bulletin of the World Health Organization, vol. 81, no. 9, pp. 646-656, 2003.

[12] L. S. Lohmander, M. G. de Verdier, J. Rollof, P. M. Nilsson, and G. Engström, "Incidence of severe knee and hip osteoarthritis in relation to different measures of body mass: a population-based prospective cohort study," Annals of the Rheumatic Diseases, vol. 68, no. 4, pp. 490-496, 2009.

[13] M. A. Weber, "Treatment of patients with hypertension and arthritis pain: new concepts," American Journal of Medicine, vol. 122, no. 5, pp. S16-S22, 2009.

[14] G. C. Curhan, W. C. Willett, B. Rosner, and M. J. Stampfer, "Frequency of analgesic use and risk of hypertension in younger women," Archives of Internal Medicine, vol. 162, no. 19, pp. 2204-2208, 2002.

[15] J. Dedier, M. J. Stampfer, S. E. Hankinson, W. C. Willett, F. E. Speizer, and G. C. Curhan, "Nonnarcotic analgesic use and the risk of hypertension in US women," Hypertension, vol. 40, no. 5, pp. 604-608, 2002.

[16] W. Zhang, R. W. Moskowitz, G. Nuki et al., "OARSI recommendations for the management of hip and knee osteoarthritis, part II: OARSI evidence-based, expert consensus guidelines," Osteoarthritis and Cartilage, vol. 16, no. 2, pp. 137-162, 2008.

[17] W. Zhang, M. Doherty, B. F. Leeb et al., "EULAR evidence based recommendations for the management of hand osteoarthritis: report of a Task Force of the EULAR Standing Committee for International Clinical Studies Including Therapeutics (ESCISIT)," Annals of the Rheumatic Diseases, vol. 66, no. 3, pp. 377-388, 2007.

[18] J. P. Forman, E. B. Rimm, and G. C. Curhan, "Frequency of analgesic use and risk of hypertension among men," Archives of Internal Medicine, vol. 167, no. 4, pp. 394-399, 2007.

[19] J. P. Forman, M. J. Stampfer, and G. C. Curhan, "Nonnarcotic analgesic dose and risk of incident hypertension in US women," Hypertension, vol. 46, no. 3, pp. 500-507, 2005.

[20] J. H. Gurwitz, J. Avorn, R. L. Bohn, R. J. Glynn, M. Monane, and H. Mogun, "Initiation of antihypertensive treatment during nonsteroidal anti-inflammatory drug therapy," Journal of the American Medical Association, vol. 272, no. 10, pp. 781-786, 1994.

[21] J. E. Pope, J. J. Anderson, and D. T. Felson, "A meta-analysis of the effects of nonsteroidal anti-inflammatory drugs on blood pressure," Archives of Internal Medicine, vol. 153, no. 4, pp. 477-484, 1993.

[22] A. G. Johnson, T. V. Nguyen, and R. O. Day, "Do nonsteroidal anti-inflammatory drugs affect blood pressure? A metaanalysis," Annals of Internal Medicine, vol. 121, no. 4, pp. 289 300, 1994.
[23] E. A. Chrischilles and R. B. Wallace, "Nonsteroidal antiinflammatory drugs and blood pressure in an elderly population," Journals of Gerontology, vol. 48, no. 3, pp. M91-M96, 1993.

[24] A. G. Johnson, L. A. Simons, J. Simons, Y. Friedlander, and J. McCallum, "Non-steroidal anti-inflammatory drugs and hypertension in the elderly: a community-based crosssectional study," British Journal of Clinical Pharmacology, vol. 35, no. 5, pp. 455-459, 1993.

[25] K. L. Radack, C. C. Deck, and S. S. Bloomfield, "Ibuprofen interferes with the efficacy of antihypertensive drugs. A randomized, double-blind, placebo-controlled trial of ibuprofen compared with acetaminophen," Annals of Internal Medicine, vol. 107, no. 5, pp. 628-635, 1987.

[26] J. P. Chalmers, M. J. West, L. M. H. Wing, A. J. Bune, and J. R. Graham, "Effects of indomethacin, sulindac, naproxen, aspirin and paracetamol in treated hypertensive patients," Clinical and Experimental Hypertension A, vol. 6, no. 6, pp. 1077-1093, 1984.

[27] J. J. Nawarskas, R. R. Townsend, M. D. Cirigliano, and S. A. Spinler, "Effect of aspirin on blood pressure in hypertensive patients taking enalapril or losartan," American Journal of Hypertension, vol. 12, no. 8, pp. 784-789, 1999.

[28] F. Avanzini, G. Palumbo, C. Alli et al., "Effects of low-dose aspirin on clinic and ambulatory blood pressure in treated hypertensive patients," American Journal of Hypertension, vol. 13, no. 6, supplement, pp. 611-616, 2000.

[29] T. Kurth, C. H. Hennekens, T. Sturmer et al., "Analgesic use and risk of subsequent hypertension in apparently healthy men," Archives of Internal Medicine, vol. 165, no. 16, pp. 1903-1909, 2005.

[30] T. J. Aw, S. J. Haas, D. Liew, and H. Krum, "Meta-analysis of cyclooxygenase-2 inhibitors and their effects on blood pressure," Archives of Internal Medicine, vol. 165, no. 5, pp. 490-496, 2005.

[31] F. Wolfe, S. Zhao, M. Reynolds, and D. Pettitt, "Blood pressure destabilization and edema among 8538 users of celecoxib, rofecoxib, and nonselective nonsteroidal antiinflammatory drugs (NSAID) and nonusers of NSAID receiving ordinary clinical care," Journal of Rheumatology, vol. 31, no. 6, pp. 1143-1151, 2004.

[32] T. M. MacDonald, J. Y. Reginster, T. W. Littlejohn et al., "Effect on blood pressure of lumiracoxib versus ibuprofen in patients with osteoarthritis and controlled hypertension: a randomized trial," Journal of Hypertension, vol. 26, no. 8, pp. 1695-1702, 2008.

[33] C. P. Cannon, S. P. Curtis, G. A. FitzGerald et al., "Cardiovascular outcomes with etoricoxib and diclofenac in patients with osteoarthritis and rheumatoid arthritis in the Multinational Etoricoxib and Diclofenac Arthritis Long-term (MEDAL) programme: a randomised comparison," Lancet, vol. 368, no. 9549, pp. 1771-1781, 2006.

[34] T. O. Morgan, A. Anderson, and D. Bertram, "Effect of indomethacin on blood pressure in elderly people with essential hypertension well controlled on amlodipine or enalapril," American Journal of Hypertension, vol. 13, no. 11, pp. 1161-1167, 2000.

[35] W. B. White, J. Kent, A. Taylor, K. M. Verburg, J. B. Lefkowith, and A. Whelton, "Effects of celecoxib on ambulatory blood pressure in hypertensive patients on ACE inhibitors," Hypertension, vol. 39, no. 4, pp. 929-934, 2002.

[36] A. Whelton, W. B. White, A. E. Bello, J. A. Puma, and J. G. Fort, "Effects of celecoxib and rofecoxib on blood pressure and edema in patients $>$ or $=65$ years of age with 
systemic hypertension and osteoarthritis," American Journal of Cardiology, vol. 90, no. 9, pp. 959-963, 2002.

[37] G. A. Cinotti and F. Pugliese, "Prostaglandins in blood pressure regulation," Kidney International, vol. 34, no. 25, pp. S57-S60, 1988.

[38] G. A. FitzGerald, "COX-2 and beyond: approaches to prostaglandin inhibition in human disease," Nature Reviews Drug Discovery, vol. 2, no. 11, pp. 879-890, 2003.

[39] A. Whelton, G. Schulman, C. Wallemark et al., "Effects of celecoxib and naproxen on renal function in the elderly," Archives of Internal Medicine, vol. 160, no. 10, pp. 1465-1470, 2000.

[40] F. Catella-Lawson, B. Mcadam, B. W. Morrison et al., "Effects of specific inhibition of cyclooxygenase-2 on sodium balance, hemodynamics, and vasoactive eicosanoids," Journal of Pharmacology and Experimental Therapeutics, vol. 289, no. 2, pp. 735-741, 1999.

[41] C. Patrono and M. J. Dunn, "The clinical significance of inhibition of renal prostaglandin synthesis," Kidney International, vol. 32, no. 1, pp. 1-12, 1987.

[42] J. Rossat, M. Maillard, J. Nussberger, H. R. Brunner, and M. Burnier, "Renal effects of selective cyclooxygenase-2 inhibition in normotensive salt-depleted subjects," Clinical Pharmacology and Therapeutics, vol. 66, no. 1, pp. 76-84, 1999.

[43] A. G. Johnson, T. V. Nguyen, R. Owe-Young, D. J. Williamson, and R. O. Day, "Potential mechanisms by which nonsteroidal anti-inflammatory drugs elevate blood pressure: the role of endothelin-1," Journal of Human Hypertension, vol. 10, no. 4, pp. 257-261, 1996.

[44] L. S. Lohmander, D. McKeith, O. Svensson et al., "A randomised, placebo controlled, comparative trial of the gastrointestinal safety and efficacy of AZD3582 versus naproxen in osteoarthritis," Annals of the Rheumatic Diseases, vol. 64, no. 3, pp. 449-456, 2005.

[45] T. J. Schnitzer, A. J. Kivitz, R. S. Lipetz, N. Sanders, and A. Hee, "Comparison of the COX-inhibiting nitric oxide donator AZD3582 and rofecoxib in treating the signs and symptoms of osteoarthritis of the knee," Arthritis \& Rheumatism, vol. 53, no. 6, pp. 827-837, 2005.

[46] C. Naproxcinod Baerwald, P. Verdecchia, B. Duquesroix, H. Frayssinet, and T. Ferreira, "Efficacy, safety and effects on BP of Naproxcinod $750 \mathrm{Mg}$ bid compared with Placebo and Naproxen $500 \mathrm{Mg}$ bid in patients with osteoarthritis of the hip," Arthritis \& Rheumatism, vol. 62, no. 12, pp. 3635-3644, 2010.

[47] T. J. Schnitzer, M. C. Hochberg, C. E. Marrero, B. Duquesroix, H. Frayssinet, and M. Beekman, "Efficacy and safety of naproxcinod in patients with osteoarthritis of the knee: a 53week prospective randomized multicenter study," Seminars in Arthritis and Rheumatism, vol. 40, no. 4, pp. 285-297, 2011.

[48] R. L. Prentice, "On the ability of blood pressure effects to explain the relation between oral contraceptives and cardiovascular disease," American Journal of Epidemiology, vol. 127, no. 2, pp. 213-219, 1988.

[49] T. Rosenthal and S. Oparil, "Oral contraceptives, hormones replacement therapy, and hypertension," in Comprehensive Hypertension, G. Lip and J. Hall, Eds., Elsevier/Mosby, New York, NY, USA, 2007.

[50] L. Chasan-Taber, W. C. Willett, J. E. Manson et al., "Prospective study of oral contraceptives and hypertension among women in the United States," Circulation, vol. 94, no. 3, pp. 483-489, 1996.
[51] J. N. Lubianca, C. S. Faccin, and F. D. Fuchs, "Oral contraceptives: a risk factor for uncontrolled blood pressure among hypertensive women," Contraception, vol. 67, no. 1, pp. 19-24, 2003.

[52] W. B. White, V. Hanes, V. Chauhan, and B. Pitt, "Effects of a new hormone therapy, drospirenone and 17- $\beta$-estradiol, in postmenopausal women with hypertension," Hypertension, vol. 48, no. 2, pp. 246-253, 2006.

[53] World Health Organization, "Low dose combined oral contraceptives," in Improving Access to Quality Care in Family Planning: Medical Eligibility Criteria for Contraceptive Use, WHO, Geneva, Switzerland, 3rd edition, 2004.

[54] American College of Obstetricians and Gynecologists Practice Bulletin, "Use of hormonal contraception in women with coexisting medical conditions: clinical management guidelines for obstetrician-gynecologists," Obstetrics \& Gynecology, vol. 107, pp. 1453-1472, 2006.

[55] N. Ferrara, K. J. Hillan, H. P. Gerber, and W. Novotny, "Discovery and development of bevacizumab, an anti-VEGF antibody for treating cancer," Nature Reviews Drug Discovery, vol. 3, no. 5, pp. 391-400, 2004.

[56] H. Hurwitz, L. Fehrenbacher, W. Novotny et al., "Bevacizumab plus irinotecan, fluorouracil, and leucovorin for metastatic colorectal cancer," New England Journal of Medicine, vol. 350, no. 23, pp. 2335-2342, 2004.

[57] S. Shinkaruk, M. Bayle, G. Lain, and G. Deleris, "Vascular Endothelial Cell Growth Factor (VEGF), an emerging target for cancer chemotherapy," Current Medicinal ChemistryAnti-Cancer Agents, vol. 3, no. 2, pp. 95-117, 2003.

[58] D. A. Sica, "Angiogenesis inhibitors and hypertension: an emerging issue," Journal of Clinical Oncology, vol. 24, no. 9, pp. 1329-1331, 2006.

[59] H. M. W. Verheul and H. M. Pinedo, "Possible molecular mechanisms involved in the toxicity of angiogenesis inhibition," Nature Reviews Cancer, vol. 7, no. 6, pp. 475-485, 2007.

[60] X. Zhu, S. Wu, W. L. Dahut, and C. R. Parikh, "Risks of proteinuria and hypertension with bevacizumab, an antibody against vascular endothelial growth factor: systematic review and meta-analysis," American Journal of Kidney Diseases, vol. 49, no. 2, pp. 186-193, 2007.

[61] S. Wu, J. J. Chen, A. Kudelka, J. Lu, and X. Zhu, "Incidence and risk of hypertension with sorafenib in patients with cancer: a systematic review and meta-analysis," Lancet Oncology, vol. 9, no. 2, pp. 117-123, 2008.

[62] X. Zhu, K. Stergiopoulos, and S. Wu, "Risk of hypertension and renal dysfunction with an angiogenesis inhibitor sunitinib: systematic review and meta-analysis," Acta Oncologica, vol. 48, no. 1, pp. 9-17, 2009.

[63] J. P. Spano, C. Chodkiewicz, J. Maurel et al., "Efficacy of gemcitabine plus axitinib compared with gemcitabine alone in patients with advanced pancreatic cancer: an open-label randomised phase II study," Lancet, vol. 371, no. 9630, pp. 2101-2108, 2008.

[64] G. Friberg, K. Kasza, E. E. Vokes, and H. L. Kindler, "Early hypertension as a potential pharmacodynamic marker for survival in pancreatic cancer patients treated with bevacizumab and gemcitabine," Journal of Clinical Oncology, vol. 23, no. 16S, part I, article 3020, 2005.

[65] B. P. Schneider, M. Wang, M. Radovich et al., "Association of vascular endothelial growth factor and vascular endothelial growth factor receptor- 2 genetic polymorphisms with outcome in a trial of paclitaxel compared with paclitaxel plus bevacizumab in advanced breast cancer: ECOG 2100," Journal of Clinical Oncology, vol. 26, no. 28, pp. 4672-4678, 2008. 
[66] J. D. Hood, C. J. Meininger, M. Ziche, and H. J. Granger, "VEGF upregulates ecNOS message, protein, and NO production in human endothelial cells," American Journal of Physiology-Heart and Circulatory Physiology, vol. 274, no. 3, pp. H1054-H1058, 1998.

[67] D. S. Gelinas, P. N. Bernatchez, S. Rollin, N. G. Bazan, and M. G. Sirois, "Immediate and delayed VEGF-mediated NO synthesis in endothelial cells: role of PI3K, PKC and PLC pathways," British Journal of Pharmacology, vol. 137, no. 7, pp. 1021-1030, 2002.

[68] J. R. Horowitz, A. Rivard, R. van der Zee et al., "Vascular endothelial growth factor/vascular permeability factor produces nitric oxide-dependent hypotension: evidence for a maintenance role in quiescent adult endothelium," Arteriosclerosis, Thrombosis, and Vascular Biology, vol. 17, no. 11, pp. 2793-2800, 1997.

[69] D. D. Ku, J. K. Zaleski, S. Liu, and T. A. Brock, "Vascular endothelial growth factor induces EDRF-dependent relaxation in coronary arteries," American Journal of Physiology-Heart and Circulatory Physiology, vol. 265, no. 2, pp. H586-H592, 1993.

[70] H. He, V. J. Venema, X. Gu, R. C. Venema, M. B. Marrero, and R. B. Caldwell, "Vascular endothelial growth factor signals endothelial cell production of nitric oxide and prostacyclin through Flk-1/KDR activation of c-Src," Journal of Biological Chemistry, vol. 274, no. 35, pp. 25130-25135, 1999.

[71] C. Wheeler-Jones, R. Abu-Ghazaleh, R. Cospedal, R. A. Houliston, J. Martin, and I. Zachary, "Vascular endothelial growth factor stimulates prostacyclin production and activation of cytosolic phospholipase A in endothelial cells via p42/p44 mitogen-activated protein kinase," FEBS Letters, vol. 420, no. 1, pp. 28-32, 1997.

[72] I. I. H. Chen, R. L. Prewitt, and R. F. Dowell, "Microvascular rarefaction in spontaneously hypertensive rat cremaster muscle," American Journal of Physiology-Heart and Circulatory Physiology, vol. 10, no. 3, pp. H306-H310, 1981.

[73] F. M. Hansen-Smith, L. W. Morris, A. S. Greene, and J. H. Lombard, "Rapid microvessel rarefaction with elevated salt intake and reduced renal mass hypertension in rats," Circulation Research, vol. 79, no. 2, pp. 324-330, 1996.

[74] P. M. Hutchins, C. D. Lynch, P. T. Cooney, and K. A. Curseen, "The microcirculation in experimental hypertension and aging," Cardiovascular Research, vol. 32, no. 4, pp. 772-780, 1996.

[75] J. J. Mourad, G. des Guetz, H. Debbabi, and B. I. Levy, "Blood pressure rise following angiogenesis inhibition by bevacizumab. A crucial role for microcirculation," Annals of Oncology, vol. 19, no. 5, pp. 927-934, 2008.

[76] N. Steeghs, H. Gelderblom, J. O. Roodt et al., "Hypertension and rarefaction during treatment with telatinib, a Small molecule angiogenesis inhibitor," Clinical Cancer Research, vol. 14, no. 11, pp. 3470-3476, 2008.

[77] M. L. Veronese, A. Mosenkis, K. T. Flaherty et al., "Mechanisms of hypertension associated with BAY 43-9006," Journal of Clinical Oncology, vol. 24, no. 9, pp. 1363-1369, 2006.

[78] S. Bottiglieri, B. Muluneh, S. Sutphin et al., "Blood pressure control in patients receiving bevacizumab in an outpatient cancer center," Journal of Oncology Pharmacy Practice. In press.

[79] O. Mir, R. Coriat, S. Ropert et al., "Treatment of bevacizumab-induced hypertension by amlodipine," Investigational New Drugs. In press.
[80] K. M. Hita, T. B. Young, T. Bidwell, M. Palta, J. B. Skatrud, and J. Dempsey, "Sleep apnea and hypertension: a population-based study," Annals of Internal Medicine, vol. 120, no. 5, pp. 382-388, 1994.

[81] H. Kraiczi, Y. Peker, K. Caidahl, A. Samuelsson, and J. Hedner, "Blood pressure, cardiac structure and severity of obstructive sleep apnea in a sleep clinic population," Journal of Hypertension, vol. 19, no. 11, pp. 2071-2078, 2001.

[82] P. E. Peppard, T. Young, M. Palta, and J. Skatrud, "Prospective study of the association between sleep-disordered breathing and hypertension," New England Journal of Medicine, vol. 342, no. 19, pp. 1378-1384, 2000.

[83] F. Javier Nieto, T. B. Young, B. K. Lind et al., "Association of sleep-disordered breathing sleep apnea, and hypertension in a large community-based study," Journal of the American Medical Association, vol. 283, no. 14, pp. 1829-1836, 2000.

[84] H. Isaksson and E. Svanborg, "Obstructive sleep apnea syndrome in male hypertensives, refractory to drug therapy. Nocturnal automatic blood pressure measurements-an aid to diagnosis?" Clinical and Experimental Hypertension A, vol. 13, no. 6-7, pp. 1195-1212, 1991.

[85] A. G. Logan, S. M. Perlikowski, A. Mente et al., "High prevalence of unrecognized sleep apnoea in drug-resistant hypertension," Journal of Hypertension, vol. 19, no. 12, pp. 2271-2277, 2001.

[86] M. N. Pratt-Ubunama, M. K. Nishizaka, R. L. Boedefeld, S. S. Cofield, S. M. Harding, and D. A. Calhoun, "Plasma aldosterone is related to severity of obstructive sleep apnea in subjects with resistant hypertension," Chest, vol. 131, no. 2, pp. 453-459, 2007.

[87] P. Lloberes, L. Lozano, G. Sampol et al., "Obstructive sleep apnoea and 24-h blood pressure in patients with resistant hypertension," Journal of Sleep Research, vol. 19, no. 4, pp. 597-602, 2010.

[88] S. C. Goncalves, D. Martinez, M. Gus et al., "Obstructive sleep apnea and resistant hypertension: a case-control study," Chest, vol. 132, no. 6, pp. 1858-1862, 2007.

[89] L. S. Doherty, J. L. Kiely, V. Swan, and W. T. McNicholas, "Long-term effects of nasal continuous positive airway pressure therapy on cardiovascular outcomes in sleep apnea syndrome," Chest, vol. 127, no. 6, pp. 2076-2084, 2005.

[90] J. M. Marin, S. J. Carrizo, E. Vicente, and A. G. N. Agusti, "Long-term cardiovascular outcomes in men with obstructive sleep apnoea-hypopnoea with or without treatment with continuous positive airway pressure: an observational study," Lancet, vol. 365, no. 9464, pp. 1046-1053, 2005.

[91] N. J. Ali, R. J. O. Davies, J. A. Fleetham, and J. R. Stradling, "The acute effects of continuous positive airway pressure and oxygen administration on blood pressure during obstructive sleep apnea," Chest, vol. 101, no. 6, pp. 1526-1532, 1992.

[92] J. E. Dimsdale, J. S. Loredo, and J. Profant, "Effect of continuous positive airway pressure on blood pressure: a placebo trial," Hypertension, vol. 35, no. 1, pp. 144-147, 2000.

[93] J. F. Faccenda, T. W. Mackay, N. A. Boon, and N. J. Douglas, "Randomized placebo-controlled trial of continuous positive airway pressure on blood pressure in the sleep apnea-hypopnea syndrome," American Journal of Respiratory and Critical Care Medicine, vol. 163, no. 2, pp. 344-348, 2001.

[94] F. Barbé, L. R. Mayoralas, J. Duran et al., "Treatment with continuous positive airway pressure is not effective in patients with sleep apnea but no daytime sleepiness: a randomized, controlled trial," Annals of Internal Medicine, vol. 134, no. 11, pp. 1015-1023, 2001. 
[95] J. C. T. Pepperell, S. Ramdassingh-Dow, N. Crosthwaite et al., "Ambulatory blood pressure after therapeutic and subtherapeutic nasal continuous positive airway pressure for obstructive sleep apnoea: a randomised parallel trial," Lancet, vol. 359, no. 9302, pp. 204-210, 2002.

[96] M. Barnes, D. Houston, C. J. Worsnop et al., "A randomized controlled trial of continuous positive airway pressure in mild obstructive sleep apnea," American Journal of Respiratory and Critical Care Medicine, vol. 165, no. 6, pp. 773-780, 2002.

[97] H. F. Becker, A. Jerrentrup, T. Ploch et al., "Effect of nasal continuous positive airway pressure treatment on blood pressure in patients with obstructive sleep apnea," Circulation, vol. 107, no. 1, pp. 68-73, 2003.

[98] D. Norman, J. S. Loredo, R. A. Nelesen et al., "Effects of continuous positive airway pressure versus supplemental oxygen on 24-hour ambulatory blood pressure," Hypertension, vol. 47, no. 5, pp. 840-845, 2006.

[99] G. V. Robinson, D. M. Smith, B. A. Langford, R. J. O. Davies, and J. R. Stradling, "Continuous positive airway pressure does not reduce blood pressure in nonsleepy hypertensive OSA patients," European Respiratory Journal, vol. 27, no. 6, pp. 1229-1235, 2006.

[100] F. Campos-Rodriguez, A. Grilo-Reina, J. Perez-Ronchel et al., "Effect of continuous positive airway pressure on ambulatory $\mathrm{BP}$ in patients with sleep apnea and hypertension: a placebocontrolled trial," Chest, vol. 129, no. 6, pp. 1459-1467, 2006.

[101] D. S. Hui, K. W. To, F. W. Ko et al., "Nasal CPAP reduces systemic blood pressure in patients with obstructive sleep apnoea and mild sleepiness," Thorax, vol. 61, no. 12, pp. 1083-1090, 2006.

[102] S. R. Coughlin, L. Mawdsley, J. A. Mugarza, J. P. H. Wilding, and P. M. A. Calverley, "Cardiovascular and metabolic effects of CPAP in obese males with OSA," European Respiratory Journal, vol. 29, no. 4, pp. 720-727, 2007.

[103] M. Kohler, J. C. T. Pepperell, B. Casadei et al., "CPAP and measures of cardiovascular risk in males with OSAS," European Respiratory Journal, vol. 32, no. 6, pp. 1488-1496, 2008.

[104] F. Campos-Rodriguez, J. Perez-Ronchel, A. Grilo-Reina, J. Lima-Alvarez, M. A. Benitez, and C. Almeida-Gonzalez, "Long-term effect of continuous positive airway pressure on BP in patients with hypertension and sleep apnea," Chest, vol. 132, no. 6, pp. 1847-1852, 2007.

[105] F. Barbe, J. Duran-Cantolla, F. Capote et al., "Long-term effect of continuous positive airway pressure in hypertensive patients with sleep apnea," American Journal of Respiratory and Critical Care Medicine, vol. 181, no. 7, pp. 718-726, 2010.

[106] N. Jaimchariyatam, C. L. Rodriguez, and K. Budur, "Does CPAP treatment in mild obstructive sleep apnea affect blood pressure?" Sleep Medicine, vol. 11, no. 9, pp. 837-842, 2010.

[107] L. A. Bazzano, Z. Khan, K. Reynolds, and J. He, "Effect of nocturnal nasal continuous positive airway pressure on blood pressure in obstructive sleep apnea," Hypertension, vol. 50, no. 2, pp. 417-423, 2007.

[108] P. Haentjens, A. van Meerhaeghe, A. Moscariello et al., "The impact of continuous positive airway pressure on blood pressure in patients with obstructive sleep apnea syndrome: evidence from a meta-analysis of placebo-controlled randomized trials," Archives of Internal Medicine, vol. 167, no. 8, pp. 757-765, 2007.
[109] M. Alajmi, A. T. Mulgrew, J. Fox et al., "Impact of continuous positive airway pressure therapy on blood pressure in patients with obstructive sleep apnea hypopnea: a metaanalysis of randomized controlled trials," Lung, vol. 185, no. 2, pp. 67-72, 2007.

[110] J.-L. Pépin, R. Tamisier, G. Barone-Rochette, S. H. Launois, P. Lévy, and J.-P. Baguet, "Comparison of continuous positive airway pressure and valsartan in hypertensive patients with sleep apnea," American Journal of Respiratory and Critical Care Medicine, vol. 182, no. 7, pp. 954-960, 2010.

[111] G. V. Robinson, J. R. Stradling, R. J. O. Davies et al., "Sleep - 6: obstructive sleep apnoea/hypopnoea syndrome and hypertension," Thorax, vol. 59, no. 12, pp. 1089-1094, 2004.

[112] A. G. Logan, R. Tkacova, S. M. Perlikowski et al., "Refractory hypertension and sleep apnoea: effect of CPAP on blood pressure and baroreflex," European Respiratory Journal, vol. 21, no. 2, pp. 241-247, 2003.

[113] M. A. Martínez-García, R. Gómez-Aldaraví, J. J. SolerCataluña, T. G. Martínez, B. Bernácer-Alpera, and P. Román-Sánchez, "Positive effect of CPAP treatment on the control of difficult-to-treat hypertension," European Respiratory Journal, vol. 29, no. 5, pp. 951-957, 2007.

[114] T. A. Dernaika, G. T. Kinasewitz, and M. M. Tawk, "Effects of nocturnal continuous positive airway pressure therapy in patients with resistant hypertension and obstructive sleep apnea," Journal of Clinical Sleep Medicine, vol. 5, no. 2, pp. 103-107, 2009.

[115] L. Lozano, J. L. Tovar, G. Sampol et al., "Continuous positive airway pressure treatment in sleep apnea patients with resistant hypertension: a randomized, controlled trial," Journal of Hypertension, vol. 28, pp. 2161-2168, 2010.

[116] C. J. Stepnowsky Jr. and P. J. Moore, "Nasal CPAP treatment for obstructive sleep apnea: developing a new perspective on dosing strategies and compliance," Journal of Psychosomatic Research, vol. 54, no. 6, pp. 599-605, 2003.

[117] H. M. Engleman and M. R. Wild, "Improving CPAP use by patients with the sleep apnoea/hypopnoea syndrome (SAHS)," Sleep Medicine Reviews, vol. 7, no. 1, pp. 81-99, 2003.

[118] T. E. Weaver and R. R. Grunstein, "Adherence to continuous positive airway pressure therapy: the challenge to effective treatment," Proceedings of the American Thoracic Society, vol. 5, no. 2, pp. 173-178, 2008.

[119] H. Kraiczi, J. Hedner, Y. Peker, and L. Grote, "Comparison of atenolol, amlodipine, enalapril, hydrochlorothiazide, and losartan for antihypertensive treatment in patients with obstructive sleep apnea," American Journal of Respiratory and Critical Care Medicine, vol. 161, no. 5, pp. 1423-1428, 2000.

[120] K. Gaddam, E. Pimenta, S. J. Thomas et al., "Spironolactone reduces severity of obstructive sleep apnoea in patients with resistant hypertension: a preliminary report," Journal of Human Hypertension, vol. 24, no. 8, pp. 532-537, 2010.

[121] J. W. Conn, "Presidential address. Part I. Painting background. Part II. Primary aldosteronism, a new clinical syndrome," Journal of Laboratory and Clinical Medicine, vol. 45, no. 1, pp. 3-17, 1955.

[122] N. M. Kaplan, "Is there an unrecognized epidemic of primary aldosteronism? Con.," Hypertension, vol. 50, no. 3, pp. 454-458, 2007.

[123] D. A. Calhoun and N. M. Kaplan, "Is there an unrecognized epidemic of primary aldosteronism? (Pro)," Hypertension, vol. 50, no. 3, pp. 447-458, 2007. 
[124] N. M. Kaplan, "Hypokalemia in the hypertensive patient, with observations on the incidence of primary aldosteronism," Annals of Internal Medicine, vol. 66, no. 6, pp. 1079-1090, 1967.

[125] A. M. Sinclair, C. G. Isles, I. Brown, H. Cameron, G. D. Murray, and J. W. Robertson, "Seconary hypertension in a blood pressure clinic," Archives of Internal Medicine, vol. 147, no. 7, pp. 1289-1296, 1987.

[126] R. W. Gifford Jr., "Evaluation of the hypertensive patient with emphasis on detecting curable causes," Milbank Memorial Fund Quarterly, vol. 47, pp. 170-186, 1969.

[127] G. S. Andersen, D. B. Toftdahl, J. O. Lund, S. Strandgaard, and P. E. Nielsen, "The incidence rate of phaeochromocytoma and Conn's syndrome in Denmark, 1977-1981," Journal of Human Hypertension, vol. 2, no. 3, pp. 187-189, 1988.

[128] P. O. Lim, P. Rodgers, K. Cardale, A. D. Watson, and T. M. MacDonald, "Potentially high prevalence of primary aldosteronism in a primary-care population," Lancet, vol. 353, no. 9146, article 40, 1999.

[129] P. Mulatero, M. Stowasser, K. C. Loh et al., "Increased diagnosis of primary aldosteronism, including surgically correctable forms, in centers from five continents," Journal of Clinical Endocrinology and Metabolism, vol. 89, no. 3, pp. 1045-1050, 2004.

[130] C. E. Fardella, L. Mosso, C. Gomez-Sanchez et al., "Primary hyperaldosteronism in essential hypertensives: prevalence, biochemical profile, and molecular biology," Journal of Clinical Endocrinology and Metabolism, vol. 85, no. 5, pp. 1863-1867, 2000.

[131] M. Stowasser, R. D. Gordon, T. G. Gunasekera et al., "High rate of detection of primary aldosteronism, including surgically treatable forms, after 'non-selective' screening of hypertensive patients," Journal of Hypertension, vol. 21, no. 11, pp. 2149-2157, 2003.

[132] G. L. Schwartz and S. T. Turner, "Screening for primary aldosteronism in essential hypertension: diagnostic accuracy of the ratio of plasma aldosterone concentration to plasma renin activity," Clinical Chemistry, vol. 51, no. 2, pp. 386-394, 2005.

[133] G. P. Rossi, G. Bernini, C. Caliumi et al., "A prospective study of the prevalence of primary aldosteronism in 1,125 hypertensive patients," Journal of the American College of Cardiology, vol. 48, no. 11, pp. 2293-2300, 2006.

[134] L. Mosso, C. Carvajal, A. Gonzalez et al., "Primary aldosteronism and hypertensive disease," Hypertension, vol. 42, no. 2, pp. 161-165, 2003.

[135] B. Strauch, T. Zelinka, M. Hampf, R. Bernhardt, and J. Widimsky Jr., "Prevalence of primary hyperaldosteronism in moderate to severe hypertension in the Central Europe region," Journal of Human Hypertension, vol. 17, no. 5, pp. 349-352, 2003.

[136] M. Stowasser and R. D. Gordon, "Primary aldosteronismcareful investigation is essential and rewarding," Molecular and Cellular Endocrinology, vol. 217, no. 1-2, pp. 33-39, 2004.

[137] P. Mulatero, R. G. Dluhy, G. Giacchetti, M. Boscaro, F. Veglio, and P. M. Stewart, "Diagnosis of primary aldosteronism: from screening to subtype differentiation," Trends in Endocrinology and Metabolism, vol. 16, no. 3, pp. 114-119, 2005.

[138] D. A. Calhoun, M. K. Nishizaka, M. A. Zaman, R. B. Thakkar, and P. Weissman, "High prevalence of primary aldosteronism among black and white subjects with resistant hypertension," Hypertension, vol. 40, pp. 892-896, 2002.
[139] B. J. Gallay, S. Ahmad, L. Xu, B. Toivola, and R. C. Davidson, "Screening for primary hyperaldosteronism without discontinuing hypertensive medications: plasma aldosterone-renin ratio," American Journal of Kidney Diseases, vol. 37, pp. 699-705, 2001.

[140] I. K. Eide, P. A. Torjesen, A. Drolsum, A. Babovic, and N. P. Lilledahl, "Low-renin status in therapy-resistant hypertension: a clue to efficient treatment," Journal of Hypertension, vol. 22, no. 11, pp. 2217-2226, 2004.

[141] N. Martell, M. Rodriguez-Cerrillo, D. E. Grobee et al., "High prevalence of secondary hypertension and insulin resistance in patients with refractory hypertension," Blood Press, vol. 12, pp. 149-154, 2003.

[142] G. E. Umpierrez, P. Cantey, D. Smiley et al., "Primary Aldosteronism in diabetic subjects with resistant hypertension," Diabetes Care, vol. 30, no. 7, pp. 1699-1703, 2007.

[143] S. Douma, K. Petidis, M. Doumas et al., "Prevalence of primary hyperaldosteronism in resistant hypertension: a retrospective observational study," Lancet, vol. 371, no. 9628, pp. 1921-1926, 2008.

[144] C. C. Gonzaga, K. K. Gaddam, M. I. Ahmed et al., "Severity of obstructive sleep apnea is related to aldosterone status in subjects with resistant hypertension," Journal of Clinical Sleep Medicine, vol. 6, no. 4, pp. 363-368, 2010.

[145] A. Di Murro, L. Petramala, D. Cotesta et al., "Reninangiotensin-aldosterone system in patients with sleep apnoea: prevalence of primary aldosteronism," Journal of the Renin-Angiotensin-Aldosterone System, vol. 11, no. 3, pp. 165-172, 2010.

[146] D. A. Sica, "Endocrine causes of secondary hypertension," Journal of Clinical Hypertension, vol. 10, no. 7, pp. 534-540, 2008.

[147] A. Mazza, M. Armigliato, S. Zamboni et al., "Endocrine arterial hypertension: therapeutic approach in clinical practice," Minerva Endocrinologica, vol. 33, no. 4, pp. 297-312, 2008.

[148] J. Coresh, G. L. Wei, G. McQuillan et al., "Prevalence of high blood pressure and elevated serum creatinine level in the United States: findings from the third national health and nutrition examination survey (1988-1994)," Archives of Internal Medicine, vol. 161, no. 9, pp. 1207-1216, 2001.

[149] G. Mancia, G. de Backer, A. Dominiczak et al., "2007 Guidelines for the Management of Arterial Hypertension: the Task Force for the Management of Arterial Hypertension of the European Society of Hypertension (ESH) and of the European Society of Cardiology (ESC)," Journal of Hypertension, vol. 25, no. 6, pp. 1105-1187, 2007.

[150] A. V. Chobanian, G. L. Bakris, H. R. Black et al., "Seventh report of the Joint National Committee on prevention, detection, evaluation, and treatment of high blood pressure," Hypertension, vol. 42, no. 6, pp. 1206-1252, 2003.

[151] A. S. Levey, M. V. Rocco, S. Anderson et al., "K/DOQI clinical practice guidelines on hypertension and antihypertensive agents in chronic kidney disease," American Journal of Kidney Diseases, vol. 43, no. 5, pp. 1-290, 2004.

[152] W. C. Cushman, C. E. Ford, J. A. Cutler et al., "Success and predictors of blood pressure control in diverse North American settings: the antihypertensive and lipid-lowering treatment to prevent heart attact trial (ALLHAT)," Journal of Clinical Hypertension, vol. 4, no. 6, pp. 393-404, 2002.

[153] M. G. Saelen, L. K. Prøsch, H. Gudmundsdottir et al., "Controlling systolic blood pressure is difficult in patients with diabetic kidney disease exhibiting moderate-to-severe reductions in renal function," Blood Pressure, vol. 14, no. 3, pp. 170-176, 2005. 
[154] N. M. Kaplan, "Resistant hypertension," Journal of Hypertension, vol. 23, no. 8, pp. 1441-1444, 2005.

[155] V. M. Campese, N. Mitra, and D. Sandee, "Hypertension in renal parenchymal disease: why is it so resistant to treatment?" Kidney International, vol. 69, no. 6, pp. 967-973, 2006.

[156] G. M. Singer, M. Izhar, and H. R. Black, "Goal-oriented hypertension management: translating clinical trials to practice," Hypertension, vol. 40, no. 4, pp. 464-469, 2002.

[157] J. P. Casas, W. Chua, S. Loukogeorgakis et al., "Effect of inhibitors of the renin-angiotensin system and other antihypertensive drugs on renal outcomes: systematic review and meta-analysis," Lancet, vol. 366, no. 9502, pp. 2026-2033, 2005.

[158] ONTARGET Investigators, "Telmisartan, ramipril, or both in patients at high risk for vascular events," New England Journal of Medicine, vol. 358, pp. 1547-1559, 2008.

[159] J. F. Mann, R. E. Schmieder, M. McQueen et al., "Renal outcomes with telmisartan, ramipril, or both, in people at high vascular risk (the ONTARGET study): a multicentre, randomised, double-blind, controlled trial," Lancet, vol. 372, no. 9638, pp. 547-553, 2008.

[160] P. A. Sarafidis and G. L. Bakris, "Renin-angiotensin blockade and kidney disease," Lancet, vol. 372, no. 9638, pp. 511-512, 2008.

[161] R. D. Safian and S. C. Textor, "Renal-artery stenosis," New England Journal of Medicine, vol. 344, no. 6, pp. 431-442, 2001.

[162] C. J. White, "Catheter-based therapy for atherosclerotic renal artery stenosis," Circulation, vol. 113, no. 11, pp. 1464-1473, 2006.

[163] R. A. Aqel, G. J. Zoghbi, S. A. Baldwin et al., "Prevalence of renal artery stenosis in high-risk veterans referred to cardiac catheterization," Journal of Hypertension, vol. 21, no. 6, pp. 1157-1162, 2003.

[164] R. T. Tumelero, N. T. Duda, A. P. Tognon, and M. Thiesen, "Prevalence of renal artery stenosis in 1,656 patients who have undergone cardiac catheterization," Arquivos Brasileiros de Cardiologia, vol. 87, no. 3, pp. 213-253, 2006.

[165] G. H. Anderson Jr., N. Blakeman, and D. H. P. Streeten, "The effect of age on prevalence of secondary forms of hypertension in 4429 consecutively referred patients," Journal of Hypertension, vol. 12, no. 5, pp. 609-615, 1994.

[166] J. J. Crowley, R. M. Santos, R. H. Peter et al., "Progression of renal artery stenosis in patients undergoing cardiac catheterization," American Heart Journal, vol. 136, no. 5, pp. 913-918, 1998.

[167] T. Leiner, M. W. de Haan, P. J. Nelemans, J. M. Engelshoven, and G. B. C. Vasbinder, "Contemporary imaging techniques for the diagnosis of renal artery stenosis," European Radiology, vol. 15, no. 11, pp. 2219-2229, 2005.

[168] ASTRAL Investigators, "Revascularization versus medical therapy for renal artery stenosis," New England Journal of Medicine, vol. 361, pp. 1953-1962, 2009.

[169] C. J. Cooper, T. P. Murphy, A. Matsumoto et al., "Stent revascularization for the prevention of cardiovascular and renal events among patients with renal artery stenosis and systolic hypertension: rationale and design of the CORAL trial," American Heart Journal, vol. 152, no. 1, pp. 59-66, 2006.

[170] J. J. Caro, M. Salas, J. L. Speckman, G. Raggio, and J. D. Jackson, "Persistence with treatment for hypertension in actual practice," Canadian Medical Association Journal, vol. 160, no. 1, pp. 31-37, 1999.
[171] G. Mazzaglia, L. G. Mantovani, M. C. J. M. Sturkenboom et al., "Patterns of persistence with antihypertensive medications in newly diagnosed hypertensive patients in Italy: a retrospective cohort study in primary care," Journal of Hypertension, vol. 23, no. 11, pp. 2093-2100, 2005.

[172] B. L. G. van Wijk, O. H. Klungel, E. R. Heerdink, and A. de Boer, "Rate and determinants of 10-year persistence with antihypertensive drugs," Journal of Hypertension, vol. 23, no. 11, pp. 2101-2107, 2005.

[173] B. Vrijens, G. Vincze, P. Kristanto, J. Urquhart, and M. Burnier, "Adherence to prescribed antihypertensive drug treatments: longitudinal study of electronically compiled dosing histories," British Medical Journal, vol. 336, no. 7653, pp. 1114-1117, 2008.

[174] G. Corrao, A. Zambon, A. Parodi et al., "Discontinuation of and changes in drug therapy for hypertension among newly-treated patients: a population-based study in Italy," Journal of Hypertension, vol. 26, no. 4, pp. 819-824, 2008.

[175] P. R. Conlin, W. C. Gerth, J. Fox, J. B. Roehm, and S. J. Boccuzzi, "Four-year persistence patterns among patients initiating therapy with the angiotensin II receptor antagonist losartan versus other antihypertensive drug classes," Clinical Therapeutics, vol. 23, no. 12, pp. 1999-2010, 2001.

[176] W. A. de Souza, M. Sabha, F. de Faveri Favero, G. BergstenMendes, J. C. Yugar-Toledo, and H. Moreno, "Intensive monitoring of adherence to treatment helps to identify "true" resistant hypertension," Journal of Clinical Hypertension, vol. 11, no. 4, pp. 183-191, 2009.

[177] J. Park and V. Campese, "Clinical characteristics of resistant hypertension: the importance of compliance and the role of diagnostic evaluation in delineating pathogenesis," Journal of Clinical Hypertension, vol. 9, no. 1, pp. 7-12, 2007.

[178] D. J. Hyman and V. N. Pavlik, "Self-reported hypertension treatment practices among primary care physicians: blood pressure thresholds, drug choices, and the role of guidelines and evidence-based medicine," Archives of Internal Medicine, vol. 160, no. 15, pp. 2281-2286, 2000.

[179] S. A. Oliveria, P. Lapuerta, B. D. McCarthy, G. J. L'Italien, D. R. Berlowitz, and S. M. Asch, "Physician-related barriers to the effective management of uncontrolled hypertension," Archives of Internal Medicine, vol. 162, no. 4, pp. 413-420, 2002.

[180] C. L. Trewet and M. E. Ernst, "Resistant hypertension: identifying causes and optimizing treatment regimens," Southern Medical Journal, vol. 101, no. 2, pp. 166-173, 2008.

[181] L. S. Phillips, W. T. Branch, C. B. Cook et al., "Clinical inertia," Annals of Internal Medicine, vol. 135, no. 9, pp. 825-834, 2001.

[182] E. M. Furmaga, F. E. Cunningham, W. C. Cushman et al., "National utilization of antihypertensive medications from 2000-2006 in the Veterans Health Administration: focus on thiazides diuretics," Journal of Clinical Hypertension, vol. 10, pp. 770-778, 2008.

[183] B. M. Egan, Y. Zhao, and R. N. Axon, "US trends in prevalence, awareness, treatment, and control of hypertension, 1988-2008," Journal of the American Medical Association, vol. 303, no. 20, pp. 2043-2050, 2010.

[184] E. Falaschetti, M. Chaudhury, J. Mindell, and N. Poulter, "Continued improvement in hypertension management in England: results from the health survey for England 2006," Hypertension, vol. 53, no. 3, pp. 480-486, 2009.

[185] N. H. McInnis, G. Fodor, M. Moy Lum-Kwong, and F. H. H. Leenen, "Antihypertensive medication use and blood pressure control: a community-based cross-sectional survey 
(ON-BP)," American Journal of Hypertension, vol. 21, no. 11, pp. 1210-1215, 2008.

[186] T. G. Pickering, J. E. Hall, L. J. Appel et al., "Recommendations for blood pressure measurement in humans and experimental animals: part 1: blood pressure measurement in humans-a statement for professionals from the Subcommittee of Professional and Public Education of the American Heart Association Council on high blood pressure research," Circulation, vol. 111, no. 5, pp. 697-716, 2005.

[187] M. Moser and J. F. Setaro, "Resistant or difficult-to-control hypertension," New England Journal of Medicine, vol. 355, no. 4, pp. 385-392, 2006.

[188] D. A. Calhoun, D. Jones, S. Textor et al., "Resistant hypertension: diagnosis, evaluation, and treatment: a scientific statement from the American Heart Association Professional Education Committee of the Council for High Blood Pressure Research," Circulation, vol. 117, pp. e510-e526, 2008.

[189] P. A. Sarafidis and G. L. Bakris, "State of hypertension management in the United States: confluence of risk factors and the prevalence of resistant hypertension," Journal of Clinical Hypertension, vol. 10, no. 2, pp. 130-139, 2008.

[190] J. Redon, C. Campos, M. L. Narciso, J. L. Rodicio, J. M. Pascual, and L. M. Ruilope, "Prognostic value of ambulatory blood pressure monitoring in refractory hypertension: a prospective study," Hypertension, vol. 31, no. 2, pp. 712-718, 1998.

[191] S. D. Pierdomenico, D. Lapenna, A. Bucci et al., "Cardiovascular outcome in treated hypertensive patients with responder, masked, false resistant, and true resistant hypertension," American Journal of Hypertension, vol. 18, no. 11, pp. 1422-1428, 2005.

[192] M. A. Brown, M. L. Buddle, and A. Martin, "Is resistant hypertension really resistant?" American Journal of Hypertension, vol. 14, no. 12, pp. 1263-1269, 2001.

[193] M. K. Nishizaka, M. A. Zaman, D. A. Calhoun et al., "Efficacy of low-dose spironolactone in subjects with resistant hypertension," American Journal of Hypertension, vol. 16, no. 11, pp. 925-930, 2003.

[194] E. Pimenta, K. K. Gaddam, S. Oparil et al., "Effects of dietary sodium reduction on blood pressure in subjects with resistant hypertension: results from a randomized trial," Hypertension, vol. 54, no. 3, pp. 475-481, 2009.

[195] L. E. Ramsay, J. H. Silas, and S. Freestone, "Diuretic treatment of resistant hypertension," British Medical Journal, vol. 281, no. 6248, pp. 1101-1103, 1980.

[196] J. Ouzan, C. Perault, A. M. Lincoff, E. Carré, and M. Mertes, "The role of spironolactone in the treatment of patients with refractory hypertension," American Journal of Hypertension, vol. 15, no. 4, pp. 333-339, 2002.

[197] A. Mahmud, M. Mahgoub, M. Hall, and J. Feely, "Does aldosterone-to-renin ratio predict the antihypertensive effect of the aldosterone antagonist spironolactone?" American Journal of Hypertension, vol. 18, no. 12, pp. 1631-1635, 2005.

[198] C. Saha, G. J. Eckert, W. T. Ambrosius et al., "Improvement in blood pressure with inhibition of the epithelial sodium channel in blacks with hypertension," Hypertension, vol. 46, no. 3, pp. 481-487, 2005.

[199] Y. Sharabi, E. Adler, A. Shamis, N. Nussinovitch, A. Markovitz, and E. Grossman, "Efficacy of add-on aldosterone receptor blocker in uncontrolled hypertension," American Journal of Hypertension, vol. 19, no. 7, pp. 750-755, 2006.
[200] F. de Souza, E. Muxfeldt, R. Fiszman, and G. Salles, "Efficacy of spironolactone therapy in patients with true resistant hypertension," Hypertension, vol. 55, no. 1, pp. 147-152, 2010.

[201] S. J. Hood, K. P. Taylor, M. J. Ashby, and M. J. Brown, "The Spironolactone, Amiloride, Losartan, and Thiazide (SALT) double-blind crossover trial in patients with lowrenin hypertension and elevated aldosterone-renin ratio," Circulation, vol. 116, no. 3, pp. 268-275, 2007.

[202] D. A. Lane, S. Shah, and D. G. Beevers, "Low-dose spironolactone in the management of resistant hypertension: a surveillance study," Journal of Hypertension, vol. 25, no. 4, pp. 891-894, 2007.

[203] N. Chapman, J. Dobson, S. Wilson et al., "Effect of spironolactone on blood pressure in subjects with resistant hypertension," Hypertension, vol. 49, no. 4, pp. 839-845, 2007.

[204] D. A. Lane and D. G. Beevers, "Amiloride $10 \mathrm{mg}$ is less effective than spironolactone $25 \mathrm{mg}$ in patients with hypertension resistant to a multidrug regime including an angiotensin-blocking agent," Journal of Hypertension, vol. 25, no. 12, pp. 2515-2516, 2007.

[205] H. K. Parthasarathy, K. Alhashmi, A. D. McMahon et al., "Does the ratio of serum aldosterone to plasma renin activity predict the efficacy of diuretics in hypertension? Results of RENALDO," Journal of Hypertension, vol. 28, no. 1, pp. 170-177, 2010.

[206] R. C. Hermida, D. E. Ayala, J. R. Fernandez, and C. Calvo, "Chronotherapy improves blood pressure control and reverts the nondipper pattern in patients with resistant hypertension," Hypertension, vol. 51, no. 1, pp. 69-76, 2008.

[207] R. Minutolo, F. B. Gabbai, S. Borrelli et al., "Changing the timing of antihypertensive therapy to reduce nocturnal blood pressure in CKD: an 8-week uncontrolled trial," American Journal of Kidney Diseases, vol. 50, no. 6, pp. 908-917, 2007.

[208] C. Tsioufis, A. Kasiakogias, C. Thomopoulos, A. Manolis, and C. Stefanadis, "Managing hypertension in obstructive sleep apnea: the interplay of continuous positive airway pressure, medication and chronotherapy," Journal of Hypertension, vol. 28, no. 5, pp. 875-882, 2010.

[209] M. A. Weber, H. Black, G. Bakris et al., "A selective endothelin-receptor antagonist to reduce blood pressure in patients with treatment-resistant hypertension: a randomised, double-blind, placebo-controlled trial," Lancet, vol. 374, no. 9699, pp. 1423-1431, 2009.

[210] G. L. Bakris, L. H. Lindholm, H. R. Black et al., "Divergent results using clinic and ambulatory blood pressures: report of a darusentan-resistant hypertension trial," Hypertension, vol. 56, no. 5, pp. 824-830, 2010.

[211] J. J. Oliver, J. W. Dear, and D. J. Webb, "Clinical potential of combined organic nitrate and phosphodiesterase type 5 inhibitor in treatment-resistant hypertension," Hypertension, vol. 56, no. 1, pp. 62-67, 2010.

[212] M. Doumas, D. Guo, and V. Papademetriou, "Carotid baroreceptor stimulation as a therapeutic target in hypertension and other cardiovascular conditions," Expert Opinion on Therapeutic Targets, vol. 13, no. 4, pp. 413-425, 2009.

[213] M. Doumas, C. Faselis, and V. Papademetriou, "Renal sympathetic denervation and systemic hypertension," American Journal of Cardiology, vol. 105, no. 4, pp. 570-576, 2010. 
[214] I. J. M. Scheffers, A. A. Kroon, J. Schmidli et al., "Novel baroreflex activation therapy in resistant hypertension: results of a European multi-center feasibility study," Journal of the American College of Cardiology, vol. 56, no. 15, pp. 1254-1258, 2010.

[215] H. Krum, M. Schlaich, R. Whitbourn et al., "Catheter-based renal sympathetic denervation for resistant hypertension: a multicentre safety and proof-of-principle cohort study," Lancet, vol. 373, no. 9671, pp. 1275-1281, 2009. 


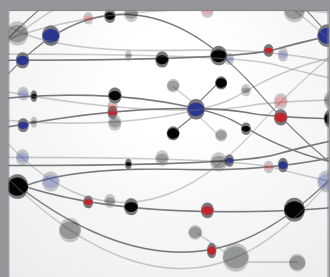

The Scientific World Journal
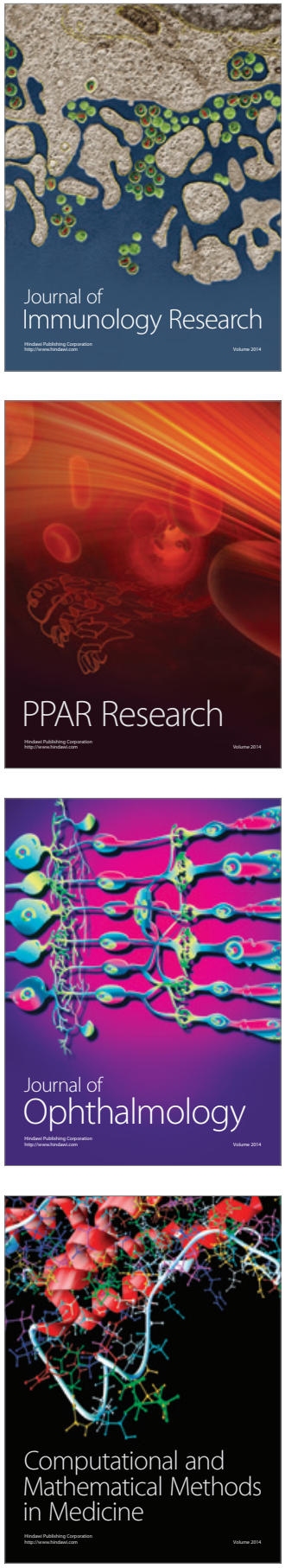

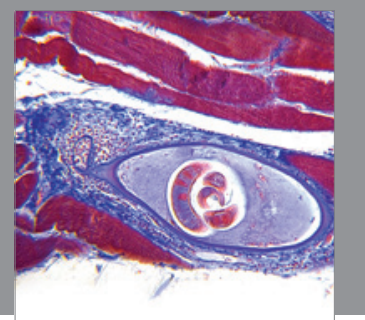

Gastroenterology

Research and Practice
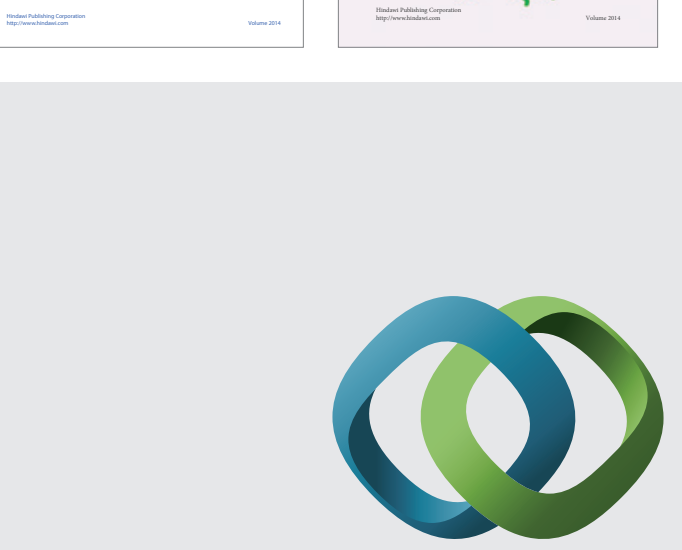

\section{Hindawi}

Submit your manuscripts at

http://www.hindawi.com
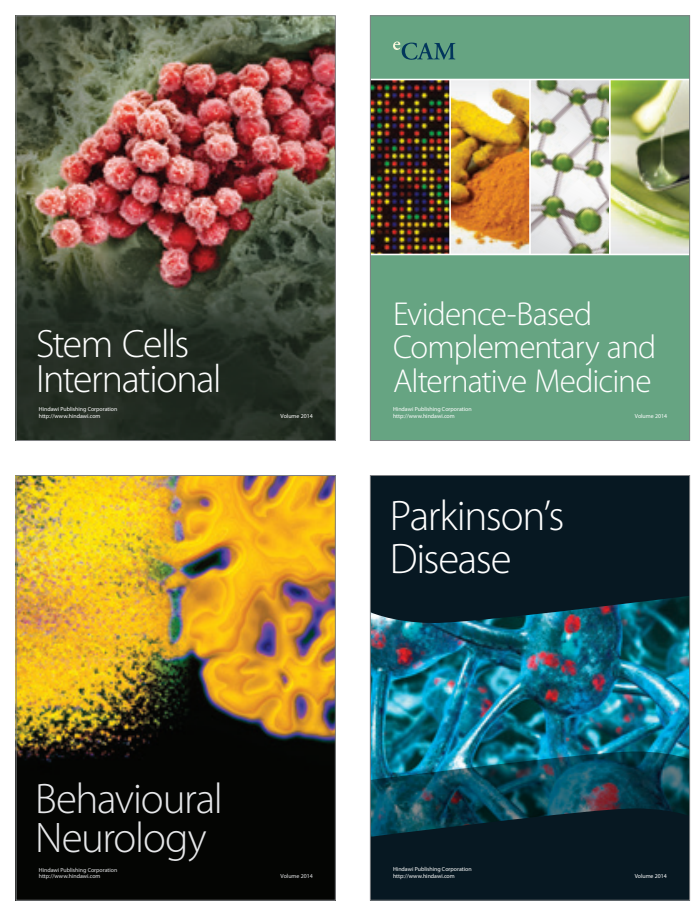

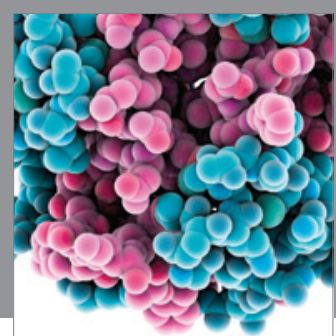

Journal of
Diabetes Research

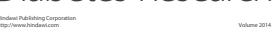

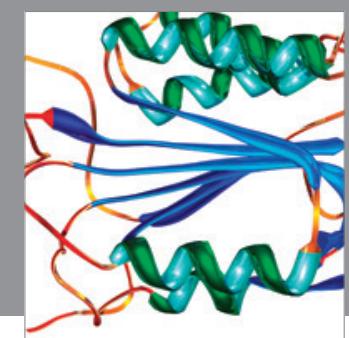

Disease Markers
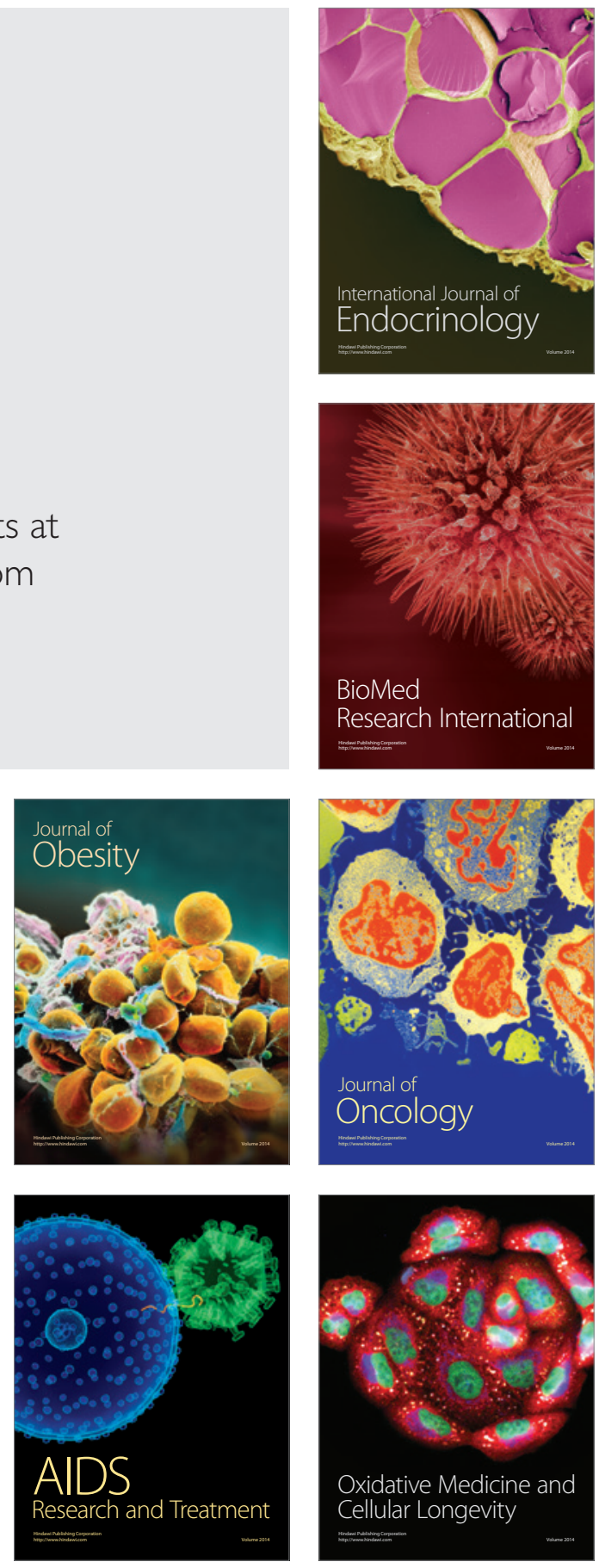